Article

\title{
Eco-Friendly Design of Reinforced Concrete Retaining Walls: Multi-objective Optimization with Harmony Search Applications
}

\author{
Aylin Ece Kayabekir ${ }^{1}$, Zülal Akbay Arama ${ }^{1, *}$, Gebrail Bekdaş ${ }^{1}{ }^{\mathbb{D}}$, Sinan Melih Nigdeli ${ }^{1}$ and \\ Zong Woo Geem ${ }^{2} *$ (D) \\ 1 Department of Civil Engineering, Istanbul University-Cerrahpaşa, Istanbul 34320, Turkey; \\ ecekayabekir@gmail.com (A.E.K.); bekdas@istanbul.edu.tr (G.B.); melihnig@istanbul.edu.tr (S.M.N.) \\ 2 College of IT Convergence, Gachon University, Seongnam 13120, Korea \\ * Correspondence: zakbay@istanbul.edu.tr (Z.A.A.); geem@gachon.ac.kr (Z.W.G.)
}

Received: 15 June 2020; Accepted: 27 July 2020; Published: 29 July 2020

\begin{abstract}
In this study, considering the eco-friendly design necessities of reinforced concrete structures, the acquirement of minimizing both the cost and the $\mathrm{CO}_{2}$ emission of the reinforced concrete retaining walls in conjunction with ensuring stability conditions has been investigated using harmony search algorithm. Optimization analyses were conducted with the use of two different objective functions to discover the contribution rate of variants to the cost and $\mathrm{CO}_{2}$ emission individually. Besides this, the integrated relationship of cost and $\mathrm{CO}_{2}$ emission was also identified by multi-objective analysis in order to identify an eco-friendly and cost-effective design. The height of the stem and the width of the foundation were treated as design variables. Several optimization cases were fictionalized in relation with the change of the depth of excavation, the amount of the surcharge applied at the top of the wall system at the backfill side, the unit weight of the backfill soil, the costs, and $\mathrm{CO}_{2}$ emission amounts of both the concrete and the reinforcement bars. Consequently, the results of the optimization analyses were arranged to discover the possibility of supplying an eco-friendly design of retaining walls with the minimization of both cost and gas emission depending upon the comparison of outcomes of the identified objective functions. The proposed approach is effective to find both economic and ecological results according to hand calculations and flower pollination algorithm.
\end{abstract}

Keywords: reinforced concrete; retaining walls; harmony search algorithm; $\mathrm{CO}_{2}$ emission; optimization

\section{Introduction}

In recent years, the sustainable success of the construction sector of the countries is not only based on the exhibited huge increase of the structuring, but also dependent upon the reliable and lasting behavior of their long-term usage [1]. The long-term usage of the constructed systems necessitates to ensure structural safety and environmental orientation against the safety of the world, considering the present and the future of the global community [2]. In this regard, considering climate change and the global warming trouble that have become the principal challenges of current civilization [3], a growing requirement to reduce the energy consumption and the gas emissions has been born. Therefore, nowadays, the design process of construction is focused on the limitation of the gas emissions, especially including the minimization of the amount of the carbon dioxide to protect the environment $[3,4]$. It is a known fact that reinforced concrete $(\mathrm{RC})$ usage forms the most preferred construction material due to the economic benefits [5], but reinforced concrete is not eco-friendly or compatible with the demands of sustainable development [6]. Hence, strategies aiming to reduce 
$\mathrm{CO}_{2}$ emissions experience a reduction in the environmental effect with a decrease in the used weight or volume of the material or with the use of recycled materials in place of natural aggregates or the use of the materials that have high durability [6,7]. The decrease in the used weight or volume of the components of reinforced concrete is based on the type of the structure, the design expectations, and the requirements for the safety, but this strategy may not present a common solution to obtain an acceptable design that ensures the minimization of cost and acquirement of safety simultaneously. The use of recycled materials for the construction is based on the availability of the materials and this condition may not also represent a direct solution to reduce gas emissions, especially for relatively less developed areas, depending upon the procuration process of recycled materials. The preferability of the development and application of highly durable materials procures safety against environmental protection, but also may not ensure equilibrium with the total cost of the construction. Therefore, the selection and application of the suggested strategies are related to the type of structure constructed, attainment of sustainable safety, acceptable cost, and accessibility of materials. In this connection, retaining wall construction forms a phenomenon that needs to be discovered. Retaining walls are one of the most important essential support structures that can spread a very large area based on the depth of excavation and the size of their foundation. Depending on the huge amount of construction materials needed, reinforced concrete is thought to be the most feasible type of construction material according to the ease of mobilization and inexpensiveness. However, the use of higher amounts of reinforced concrete leads to the generation of uncontrollable surplus emission of $\mathrm{CO}_{2}$ [5]. Therefore, several studies have been conducted to minimize both the cost and $\mathrm{CO}_{2}$ emission simultaneously, but the challenge of the solution of the nonlinear functions and discrete design variables of the cases make these integrated design processes a new and complicated problem. Nowadays, depending on the advances on the information and computer technologies, optimization techniques are preferred for obtaining the relationship between the cost and gas emissions of reinforced concrete structures [8].

Several studies have been performed to overcome the problem of gas emissions with the use of different algorithms by the determination of various objective functions focused on the minimization of dimensions of the structure. Molina-Morina et al. investigated the optimum solutions of buttressed earth-retaining walls using a harmony search algorithm with an intensification stage through threshold accepting, and also parametric studies have been conducted to discover the effect of wall height [9]. Besides this, Molina-Morina et al. discovered the difference between the design of reinforced concrete structures, taking into account two different objectives for the minimization of cost and $\mathrm{CO}_{2}$ emissions with the use of harmony search algorithm and the effects of pursuing a low-carbon strategy against a reduced cost one has been also tested [10]. Yepes et al. used black hole meta-heuristic optimization along with a discretization mechanism based on the max-min normalization. The geometric variables of the structure were also obtained with another algorithm for the proof the applicability of the proposed algorithm [2]. Khajehzadeh investigated the optimum design of retaining structures with the gravitational search algorithm and a new hybrid optimization algorithm that combines pattern search with the gravitational search algorithm was discovered and the author conducted numerical analyses to demonstrate the efficiency of the suggested new algorithm [11]. Aydoğdu and Akın tried a biogeography-based optimization technique to minimize cost and $\mathrm{CO}_{2}$ emissions, and a conclusion was made with the comparison of the results with the previously obtained results available in the literature [5]. Villalba et al. used a simulated annealing algorithm to solve two objective functions, such as the embedded $\mathrm{CO}_{2}$ emissions and the economic cost of reinforced concrete walls [12]. Yepes et al. defined an approach using a hybrid multi-start optimization strategic method based on a variable neighborhood search threshold acceptance strategy. The embedded $\mathrm{CO}_{2}$ emissions and the economic cost of reinforced concrete walls at various stages of materials were investigated [13]. Bezerra et al. aimed to compare the carbon footprint of reinforced soil structures. Two kinds of retaining wall were used in the construction of geogrid reinforcements as an alternative to a cantilever wall made of reinforced concrete, and the emissions of $\mathrm{CO}_{2}$ were compared [14]. Zastrow et al. studied the life cycle assessments of various optimized earth retaining walls with different heights and evaluations 
in relation to the contribution range of some special elements are made [15]. Yeo and Porta studied reinforced frames under the effects of gravity and lateral loads to present an optimization approach that was developed with a view to allow the decision-makers to balance sustainability and economy [16]. Yoon et al. presented a sustainable design method to optimize the embodied energy and carbon dioxide emissions of a reinforced concrete column [17]. Sierra et al. focused on the importance of the defining social sustainability and the mentioned criteria considered the complete life of the infrastructure [18]. Besides this, Sierra et al. investigated the social sustainability of the infrastructure projects using Bayesian methods [19]. Pons et al. analyzed the life cycle assessment of earth retaining walls and estimated the ultimate load capacities [20]. Lee et al. applied a stochastic analysis of the emissions of $\mathrm{CO}_{2}$ that was developed and applied to construction fields [21]. De Medeiros and Kripka optimized reinforced concrete columns with the consideration of lots of environmental impact assessment parameters [22].

In the present study, harmony search (HS) is employed to find an eco-friendly and cost-effective reinforced concrete retaining wall design. HS is a music inspired metaheuristic algorithm like evolutionary and swarm intelligence-based algorithms, which were also hybridized with machine learning methods and other algorithms [23-25].

The optimization analysis is performed with the use of three different situations. The first situation is the solution of an objective function that only considers the cost-effective design necessities in conjunction with geotechnical and structural requirements. The second situation considers the individual component of minimum $\mathrm{CO}_{2}$ emission as the aim of the defined objective function. The third situation considers the integrated relationship of both cost-effective and eco-friendly design of retaining walls by assuming the cost and the $\mathrm{CO}_{2}$ emissions as the components of the newly defined multi-objective function. The third situation involves two different considerations to ease comparison and to designate the contribution rates of components. Besides this, the second and third situations are evaluated with the assumption of three different combinations of the amounts of $\mathrm{CO}_{2}$ emissions of both the concrete and the steel material to query the material type effect on the optimization process of the retaining walls. The height and the width of the wall are treated as the design variables of retaining wall design problem and multivariate optimization cases are fictionalized in relation with the change of the depth of excavation, the amount of the surcharge, the unit weight of the backfill soil, the $\mathrm{CO}_{2}$ emission amounts of both the concrete, and the reinforcement bars. Consequently, the results of the optimization analyses are arranged to discover the possibility of supplying an eco-friendly design of retaining walls with the minimization of both cost and gas emission, depending on the comparison of outcomes of the identified objective functions.

The paper continues with the formulations and methodology of the problem in Section 2, definition of parametric cases in Section 3, numerical results and comparison in Section 4, and finally the conclusion in Section 5.

\section{Material and Methods}

\subsection{Reinforced Concrete Retaining Walls}

Reinforced concrete retaining walls can be described as the most commonly used vertically embedded structural systems that are constructed to resist the lateral earth thrust in conjunction with the self-weight to ensure stability conditions. The common cross section of a traditional reinforced concrete retaining wall is illustrated in Figure 1a. 


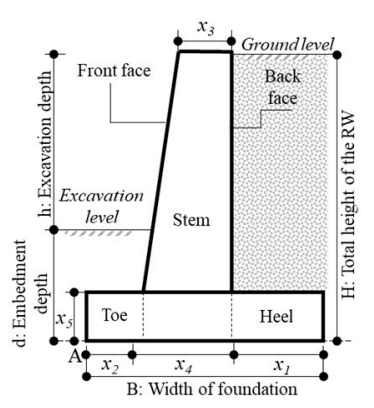

(a)

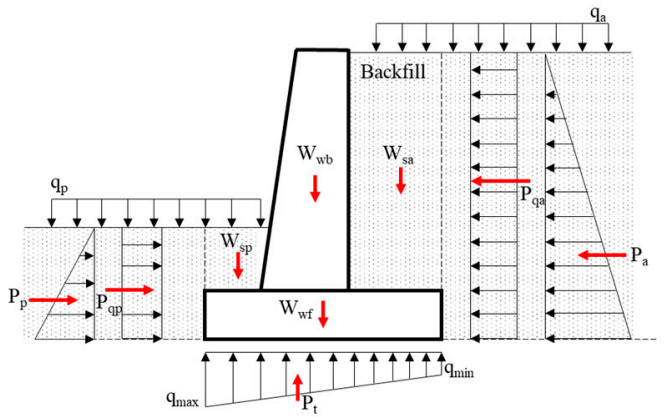

(b)

Figure 1. (a) The typical cross section of a retaining wall. (b) The stress distribution around the retaining wall.

In Figure 1, the total height of the retaining wall, the excavation depth, the embedment depth, thickness of wall foundation, thickness of wall stem at the top, thickness of wall stem at the bottom, the width of the toe, the length of the heel, and the toe of the foundation base are represented by $H, h$, $d, x_{5}, x_{3}, x_{4}, B, x_{1}, x_{2}$, respectively.

The mentioned stability conditions of retaining walls involve the satisfaction of both geotechnical safety and structural design necessities. The conventional first design step of reinforced concrete retaining walls includes the predefinition of the dimensions of the wall system, depending on the experimental knowledge. The stability considerations against the probability of sliding and overturning have to be ensured and adequate safety degrees for envisaged failure modes have to be supplied.

In this context, lateral earth pressure theories are used to evaluate the distribution of effective stresses. The well-known studies conducted to determine the lateral earth trust affected to the retaining wall systems can be identified as the suggestions of Coulomb [26], Rankine [27], Boussinesq [28], Terzahgi [29], and Jacky [30]. The usage of the proposed lateral earth pressure theories is limited according to the requirements and conditions defined in the investigated project. In the context of this study, Rankine active earth pressure theory was preferred to be used based on the selected type of soil formation and the unavailability of inclination on the ground surface to ease the calculations. The generation of the stresses through the retaining wall section is shown in Figure 1b. Both active and passive stress states are illustrated in Figure $1 b$, but the planning stage is generally formed by the absence of passive resisting stresses. When the wall is sufficiently flexible, the wall will rotate enough to allow the active earth-pressure wedge form. In this sense, only active pressures are considered to determine the effective forces of the wall system. Therefore, it is sufficient to calculate only the active lateral soil pressure coefficient for the design. The lateral active earth pressure coefficient $\left(K_{a}\right)$ can be calculated by the use of Equation (1).

$$
K_{a}=\tan ^{2}\left(45-\frac{\varnothing}{2}\right)
$$

In Figure $1 \mathrm{~b}$, the terms $q_{a}$ and $q_{p}$ represent the external surcharge loads affected from the backfill side and excavation work side of the wall, respectively. $P_{p}$ and $P_{a}, P_{q p}$ and $P_{q a}$ show the soil and external load lateral reaction forces for passive and active states, respectively. The active soil reaction force, $P_{a}$, can be calculated with Equation (2).

$$
P_{a}=\frac{1}{2} \gamma H^{2} K_{a}-2 c_{s} H \sqrt{K_{a}}
$$

The terms that are used to calculate horizontal soil forces are $\gamma, K_{a}, c_{s}$, representing the unit weight of soil, the active lateral earth pressure coefficient, and cohesion values of the soil located at the active side of the wall, respectively.

The horizontal value of distributed load that affect wall section from active side, $P_{q a}$, can be calculated by the multiplication of vertical surcharge load value with the height of the wall and with the 
active lateral earth pressure. $P_{t}$ represents the ultimate base pressure that is calculated by considering the envisaged foundation soil formation. $q_{\max }$ and $q_{\min }$ are the upper and lower boundaries of ultimate soil base pressure. $W_{w b}$ and $W_{w f}$ are the weights of the stem and base, respectively. $W_{s a}$ shows the soil weight retained on the heel of the wall foundation and $W_{s p}$ represents the soil weight retained on the toe of the wall foundation. The satisfaction of both the equilibrium of forces and moment must be supplied to obtain a safe design. The unbalanced lateral earth forces and the forces caused by the external loads lead the wall section to collapse, but the self-weight of the wall resists sliding, overturning, or failing by the inadequacy of the bearing capacity. The integrated effect of the lateral active forces can lead the wall to slide along the base. So, safety conditions must be ensured by controlling the ratio of the total lateral resistant forces $\left(\Sigma F_{R}\right)$ to the total lateral sliding forces $\left(\Sigma F_{s}\right)$. The result of the mentioned ratio given in Equation (3) must be bigger than 1.5 for static equilibrium.

$$
F o S_{s}=\frac{\Sigma F_{R}}{\Sigma F_{S}}>1.5
$$

Besides this, the wall is trying to overturn about its toe point (A point in Figure 1a) subjected to the unbalanced moment. The ratio of the total moments caused by the resisting forces $\left(\Sigma M_{R}\right)$ to the total moments activated by the sliding forces $\left(\Sigma M_{S}\right)$ must be bigger than 1.5 for static equilibrium. The resisting moments are formed due to the passive soil reaction, self-weight of the wall, weight of backfill soil, and the overturning moments are formed due to the active soil reaction forces and the distributed loads acting from the active side of the wall. Equation (4) describes the evaluation relationship of overturning safety.

$$
F_{0} S_{o}=\frac{\Sigma M_{R}}{\Sigma M_{S}}>1.5
$$

Concurrently, the satisfaction to the adequateness of the bearing capacity of the must be supplied by the ratio of ultimate base bearing pressure $\left(q_{z, u}\right)$ to the maximum soil base pressure $\left(q_{z, \text { max }}\right)$, which must be bigger than 3.0. The related correlation is given by Equation (5).

$$
F o S_{b c}=\frac{q_{z, u}}{q_{z, \max }}>3.0
$$

The upper and lower boundaries of soil base pressure can be calculated by the use of Equation (6). This equation is obtained by the inspiration of the relationships suggested for shallow foundations.

$$
q_{\min }=\frac{\Sigma V}{b}\left(1 \pm \frac{6 e}{b}\right)
$$

In Equation (6), $e$ is the eccentricity that can be calculated based on Equation (7) [31-34].

$$
e=\frac{b}{2} \frac{\Sigma M_{R}-\Sigma M_{0}}{\Sigma V}
$$

Following the supplement of stability considerations, sufficient shear and moment capacities have to be obtained and the net bearing pressure of the soil cannot be allowed to be a tensile stress and the steel of the reinforcing bars has to satisfy the adopted code requirements [35]. For this purpose, in the context of the present study, ACI 318-05 code [36] was used to generate the design constraints. The minimization of the wall bending moments has been the main topic of lots of studies to date [37-43]. However, the attainment of the structural and geotechnical design adequateness is not enough by itself and the optimum design should be a satisfactory design. The attainment of the optimum costs of structures and formation of less harmful structures to the environment connected by safe sizing should be also ensured at the design stage. In order to acquire the trio relationship between safety-cost and environmental protection, in the analysis step of this study, an optimization-based research is performed with the use of HS. 


\subsection{Optimization Methodology Using HS}

HS is a meta-heuristic algorithm that is formed by the inspiration from the musical process of the discovery in a perfect state of harmony [44]. The mentioned perfect state is calculated by the usage of an aesthetic standard. It aims to obtain a global solution as the perfect state, which is calculated by an objective function [45]. Recently, HS was employed in structural engineering problems such as the optimization of RC frame structures [46], RC beams [47], dispersed laminated composite plates [48], steel plate girders [49], analysis of plane stress systems via total potential optimization [50], and nozzle movement for additive manufacturing of concrete structures and concrete elements [51].

Five successive stages are used to reach the solution of the problems performed by HS.

Stage 1: This stage includes the definition of design constants, the boundary values of design variables, maximum iteration number, and specific parameters. The specific parameters are the harmony memory size (HMS), the harmony memory consideration rate (HMCR), and the pitch adjustment rate (PAR). A new harmony is temporized from the formation of a harmony vector with the existence of a random (rnd $(0,1)$ ) value between 0 and 1 . Equation (8) is used to define the upper $\left(X_{i, \max }\right)$ and lower $\left(X_{i, \min }\right)$ limits of each design variable $\left(X_{i}\right)$.

$$
X_{i}=X_{i, \min }+\operatorname{rnd}(0,1) \cdot\left(X_{i, \max }-X_{i, \min }\right)
$$

The design constants and design variables are used to determine the design equations and then the solution of the identified objective function is obtained. The results of the solution are stored in the harmony vector. This solution sequence is reproducible based on the HMS of harmony memory. All the generated harmony vectors are stored in a special matrix called the initial solution matrix.

Stage 2: The harmony memory consideration rate (HMCR) is used to reproduce a new vector by the selection of the proper method of solution. A random value is generated and if the determined HMCR value is more than the random one, the first way of generation (global optimization) of a new vector is chosen; if not, the second way (local optimization) is selected.

Stage 3: A new harmony vector is created by the start of the iteration process. The rules of the algorithm are used to acquire a new harmony vector with the use of different methods. For the application of the first method, the upper and lower boundaries are used as the limits to form the design variables randomly, as done in Equation (8). For the application of the second method, it is probable to use a new vector that is generated with the use of a chosen vector of the solution matrix $\left(X_{i, \text { old }}\right)$. New values $\left(X_{i, \text { new }}\right)$ are generated by adding the multiplication of pitch adjusting rate (PAR), the difference of the design variable limits, and rnd (0,1) (Equation (9)).

$$
X_{i, \text { new }}=X_{i, \text { ld }}+\operatorname{rnd}(0,1) \cdot P A R \cdot\left(X_{i, \max }-X_{i, \min }\right)
$$

Stage 4: The comparison of a new vector with stored vectors in the solution matrix is done in this stage. A new vector is used rather than the existing vector if the next vector is better than the existing one. If not, the existing condition of the solution matrix is saved. The values that are obtained from the solution of the objective function are compared and the minimum value of the solutions is selected as the best one. In the comparison process, the constraints of the design are also taken into consideration. In addition, the amounts of the violations are checked and the solution that includes the minimum violation is selected to be the better one if the violations of the design constraints exist for a new solution and existing solutions. If one of them is violated, the violated solution is eliminated.

Stage 5: The control of the stopping criterion. The iterations are stopped if a satisfactory stopping criterion is gained. The maximum iteration number was selected as the stopping criterion of the analyses in this study, although there are various ways.

In order to use HS algorithm to design retaining walls, a distinctive design parameter set is arranged. The selected design variables are classified into two groups. The first group includes the parameters in relation to the cross-section of the wall $\left(X_{1}, X_{2}, X_{3}, X_{4}, X_{5}\right)$ and the second group 
includes the parameters in relation to the reinforced concrete design $\left(X_{6}, X_{7}, X_{8}\right)$. The foreseen design parameters are given and illustrated in Table 1.

Table 1. Design variables of a reinforced concrete retaining wall.

\begin{tabular}{ccc}
\hline & Symbol & Description of Parameter \\
\hline & $X_{1}$ & Length of the heel \\
Variables in relation to & $X_{2}$ & Length of the toe \\
Cross-section dimension & $X_{3}$ & Thickness of wall stem at the top \\
& $X_{4}$ & Thickness of wall stem at the bottom \\
& $X_{5}$ & Thickness of wall foundation \\
Variables in relation to & $X_{6}$ & Area of reinforcing bars of the stem \\
reinforced concrete design & $X_{7}$ & Area of reinforcing bars of \\
& $X_{8}$ & Area of reinforcing bars of the toe
\end{tabular}

Besides this, ACI 318-05 [36] code is used to design structural part of the retaining wall. The code proposes to use the equivalent rectangular compressive stress distribution to calculate the moment capacity of the wall system. Equation (10) is used to identify the constraints of the design and $m$ notation represents the number of design constraints summarized as Table 2. If one of these constraints is not provided, the objective function of the problem is penalized by assigning a big value as $10^{6}$.

$$
g_{(j)}(x) \leq 0 \quad j=1, m
$$

The inequality function given by Equation (10) is in relation with the design variable vector that is identified by $X_{T}=\left\{X_{1}, X_{2}, \ldots, X_{n}\right\}$. In addition, the critical sections of the wall stem and the base foundation are only checked for the design of reinforcement.

Table 2. Design constraints on strength and dimensions.

\begin{tabular}{cc}
\hline Description & Constraints \\
\hline Safety for overturning & $\mathrm{g}_{1}(\mathrm{X}): \mathrm{FoS}_{\mathrm{o}, \mathrm{design}} \geq \mathrm{FoS}_{\mathrm{o}}$ \\
Safety for sliding & $\mathrm{g}_{2}(\mathrm{X}): \mathrm{FoS}_{\mathrm{s}, \mathrm{design}} \geq \mathrm{FoS}_{\mathrm{s}}$ \\
Safety for bearing capacity & $\mathrm{g}_{3}(\mathrm{X}): \mathrm{FoS}_{\mathrm{bc}, \mathrm{design}} \geq \mathrm{FoS}_{\mathrm{bc}}$ \\
\hline Minimum bearing stress $\left(q_{\text {min }}\right)$ & $\mathrm{g}_{4}(\mathrm{X}): \mathrm{q}_{\mathrm{min}} \geq 0$ \\
Flexural strength capacities of critical sections $\left(M_{d}\right)$ & $\mathrm{g}_{5-7}(\mathrm{X}): \mathrm{M}_{\mathrm{d}} \geq \mathrm{M}_{\mathrm{u}}$ \\
Shear strength capacities of critical sections $\left(V_{d}\right)$ & $\mathrm{g}_{8-10}(\mathrm{X}): \mathrm{V}_{\mathrm{d}} \geq \mathrm{V}_{\mathrm{u}}$ \\
Minimum reinforcement areas of critical sections $\left(A_{\text {smin }}\right)$ & $\mathrm{g}_{11-13}(\mathrm{X}): \mathrm{A}_{\mathrm{s}} \geq \mathrm{A}_{\mathrm{smin}}$ \\
Maximum reinforcement areas of critical sections $\left(A_{\text {smax }}\right)$ & $\mathrm{g}_{14-16}(\mathrm{X}): \mathrm{A}_{\mathrm{s}} \leq \mathrm{A}_{\mathrm{smax}}$ \\
\hline
\end{tabular}

In this study, the design of reinforced concrete retaining walls was investigated with HS algorithm using the mentioned design parameters and design constraints. The aim of the study was to obtain the cost- $\mathrm{CO}_{2}$ emission relationship within admissible limits to find an eco-friendly design of retaining structures. Four different objective functions were defined to acquire the envisaged design step by step, depending on this purpose:

i. The optimum design of reinforced concrete retaining walls with the minimization of cost according to Equation (11) (F1);

ii. The optimum design of reinforced concrete retaining walls with the minimization of $\mathrm{CO}_{2}$ emission according to Equation (12) (F2);

iii. The optimum design of reinforced concrete retaining walls with the minimization relationship of both cost and $\mathrm{CO}_{2}$ emission according to Equation (13) (F3 (1));

iv. The optimum design of reinforced concrete retaining walls with the minimization relationship of both cost and $\mathrm{CO}_{2}$ emission according to Equation (14) (F3 (2)) 
The first objective function focuses on the design of the retaining wall system with dual integration of both safety and the cost minimization. The proposed first objective function (F1) consists of four main parameters, the unit cost of the concrete; $C_{c, \text { cost }}$, the volume of concrete; $V_{c}$, the unit cost of reinforcing bars; $C_{s, \text { cost }}$ and the unit weight of reinforcing bars; $W_{s}$. The mathematical expression of the first objective function related with the total cost $\left(f_{\text {cost }}(X)\right)$ can be calculated by Equation (11).

$$
f_{\text {cost }}(X)=C_{c, \text { cost }} \cdot V_{c}+C_{s, \text { cost }} \cdot W_{s}
$$

The second objective function (F2) focuses on the design of the retaining wall system with dual integration of both safety and $\mathrm{CO}_{2}$ emission $\left(f_{\mathrm{co} 2}(X)\right)$ minimization. The suggested second objective function contains four main parameters: the $\mathrm{CO}_{2}$ emission caused by the production process of unit volume of concrete; $C_{c, c o 2}$, the volume of concrete; $V_{c}$, the $\mathrm{CO}_{2}$ emission caused by the production process of unit weight of steel; $C_{s, c o 2}$ and the unit weight of reinforcing bars; $W_{s}$. The mathematical expression of the second objective function can be calculated by Equation (12).

$$
f_{c o 2}(X)=C_{c, c o 2} \cdot V_{c}+C_{s, c o 2} \cdot W_{s}
$$

As the novel proposal of the study, the third objective function (F3) focuses on the design of the retaining wall system with trio integration of safety, cost, and $\mathrm{CO}_{2}$ emission minimization. The proposed third objective function considering both cost and $\mathrm{CO}_{2}$ emission $\left(\left(f_{a g}(X)\right)\right.$ includes four different parameters: the weight multiplier of cost; $\xi_{\text {cost }}$, the weight multiplier of $\mathrm{CO}_{2}$ emission; $\xi_{\mathrm{CO} 2}$, the cost of the design; $f_{c o s t}$ and the $\mathrm{CO}_{2}$ emission; $f_{c o 2}$. The weight multipliers are assumed to be 0.5 to reflect an equal contribution rate of both cost and $\mathrm{CO}_{2}$ emission. This function has been suggested in a way that allows to compare the cost and $\mathrm{CO}_{2}$ emission amounts expressed in two different units. $\mathrm{F} 3$ is investigated as two forms. The mathematical expression of the third objective function considering ln-based logarithm of both objectives (F3 (1)) can be calculated by Equation (13).

$$
f_{a g}(X)=\xi_{\text {cost }} \ln \left(f_{\text {cost }}\right)+\xi_{\text {co } 2} \ln \left(f_{\text {co2 }}\right)
$$

The third objective function was evaluated in a different way to compare the unique perspective of this study with other studies conducted within the literature. The third function was taken from Aydoğdu and Akin [5]. This objective function includes two non-negative weights considering both $\operatorname{cost}\left(\xi_{\text {cost }}\right)$ and $\mathrm{CO}_{2}$ emission $\left(\xi_{\mathrm{CO} 2}\right)$ weights as 1 . The mathematical expression of the objective function (F3 (2)) can be determined by Equation (14).

$$
f_{a g}(X)=\xi_{\text {cost }} f_{\text {cost }}+\xi_{\text {co } 2} f_{c o 2}
$$

The pseudo-code of HS is given as Algorithm 1:

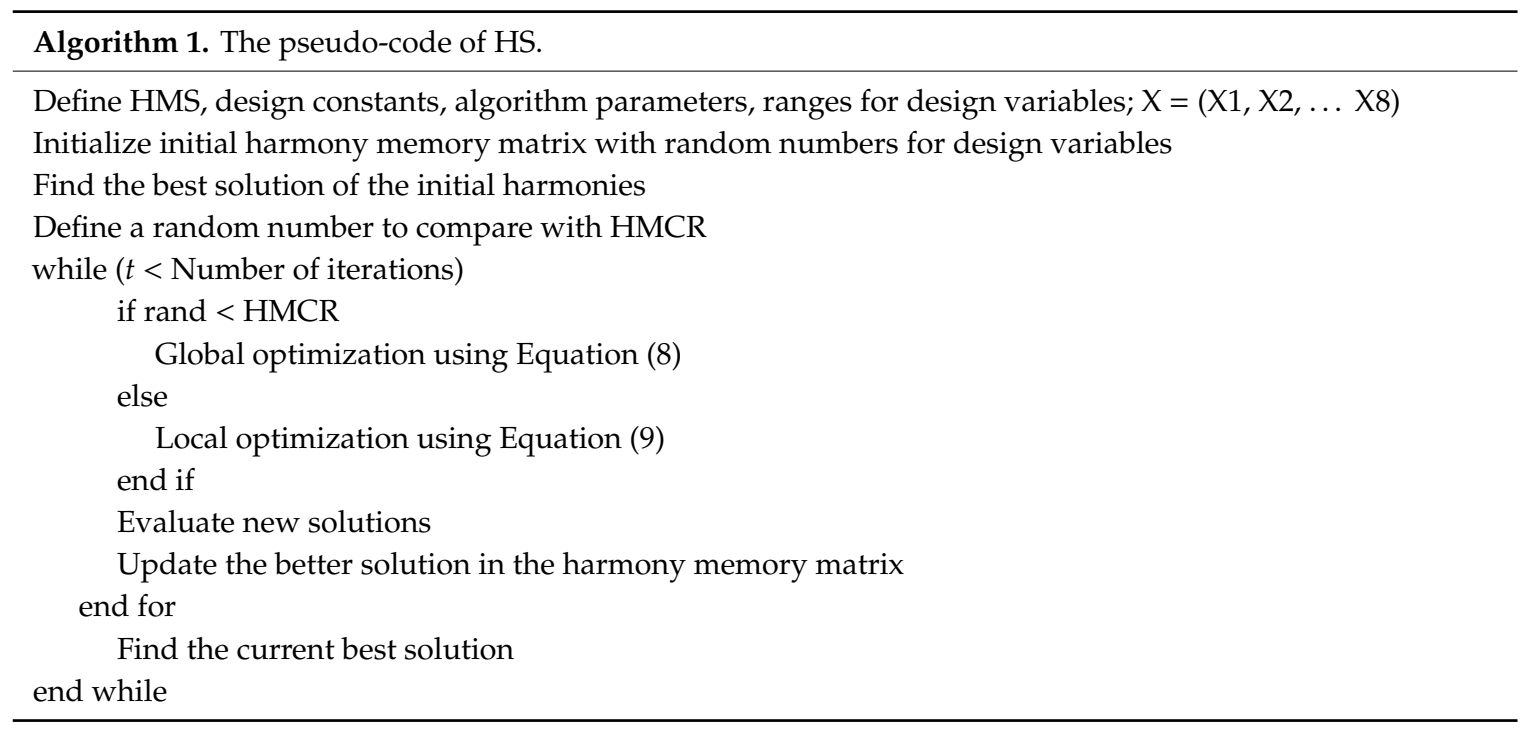




\section{Parametric Analyses}

The exemplification of the optimization process of reinforced concrete retaining walls was conducted with the parametric analyses that were arranged arbitrarily using the HS algorithm. The investigations were focused on the changes of cost, $\mathrm{CO}_{2}$ emission, and their interaction with randomly selected various excavation depths. The design of the retaining wall changed based on the excavation depth, as expected. The integrated alteration of relationships was also studied with the use of different unit costs and $\mathrm{CO}_{2}$ emissions of the concrete and steel materials. Besides, the soil formation was selected to be pure frictional with a constant internal friction angle value $\left(\phi=30^{\circ}\right)$, but the unit weight of the soil medium $(\gamma)$ was taken as various values in the analysis. The main aim was to find the interaction if it will be possible to ensure both cost saving and minimum $\mathrm{CO}_{2}$ emission with the same design dimensions which provide geotechnical safety and structural requirements, simultaneously. The selected design variables and the constants of the envisaged cases are shown in Table 3.

Table 3. The design constants and the ranges design variables.

\begin{tabular}{cccc}
\hline Symbol & Definition & Value & Unit \\
\hline$f_{y}$ & Yield strength of steel & 420 & $\mathrm{MPa}$ \\
$f_{c}$ & Compressive strength of concrete & 30 & $\mathrm{MPa}$ \\
$c_{c}$ & Concrete cover & 30 & $\mathrm{~mm}$ \\
$E_{\text {steel }}$ & Elasticity modulus of steel & 200 & $\mathrm{GPa}$ \\
$E_{\text {concrete }}$ & Elasticity modulus of concrete & 23.5 & $\mathrm{GPa}$ \\
$\gamma_{\text {steel }}$ & Unit weight of steel & 7.85 & $\mathrm{t} / \mathrm{m}^{3}$ \\
$\gamma_{\text {concrete }}$ & Unit weight of concrete & 25 & $\mathrm{kN} / \mathrm{m}^{3}$ \\
$C_{c}$ & Cost of concrete per m ${ }^{3}$ & $50,75,100,125,150$ & $\$$ \\
$C_{s}$ & Cost of steel per ton & $700,800,900,1000,1100$ & $\$$ \\
$X_{1}$ & Range of the length of the heel & $0-10$ & $\mathrm{~m}$ \\
$X_{2}$ & Range of the length of the toe & $0.2-3$ & $\mathrm{~m}$ \\
$X_{3}$ & Range of thickness of wall stem at the top & $0.2-3$ & $\mathrm{~m}$ \\
$X_{4}$ & Range of thickness of wall stem at the bottom & $0.2-3$ & $\mathrm{~m}$ \\
$X_{5}$ & Range of foundation base thickness & $0.2-3$ & $\mathrm{~m}$ \\
$\mu$ & Concrete-soil friction & tan $(2 / 3) \phi$ & - \\
\hline
\end{tabular}

The depth of excavation was selected to be between 3 and $9 \mathrm{~m}$, depending on the application limits of cantilever retaining structures in projects and based on the national and international sources [52-54].

In addition, an external surcharge load was assumed to be applied to the top of the backfill side of the wall. The magnitude of the surcharge load was selected as 0-5-10-15-20 kPa.

The unit costs of the concrete and the steel were also selected as changeable. The unit cost of the concrete for per $\mathrm{m}^{3}$ was selected to be $\$ 50, \$ 75, \$ 100, \$ 125$, and $\$ 150$ and the unit cost of the steel of the reinforcing bars for per ton was selected to be $\$ 700, \$ 800, \$ 900, \$ 1000$, and $\$ 1100$.

Besides this, the amounts of $\mathrm{CO}_{2}$ emission were also selected as different values based on literature sources $[16,55,56]$. The different emission values were used to conduct analysis with the use of objective function. The selections of amounts of emissions were approximately chosen to represent the upper and lower boundaries of the available amounts used in the literature studies. Based on the evaluated values of the amounts of emissions, three different additional analyses were arranged. The selected $\mathrm{CO}_{2}$ emission values are listed in Table 4. Yeo and Potra [16] suggested to use $\mathrm{CO}_{2}$ emission amount $376 \mathrm{~kg}$ for concrete which has $30 \mathrm{MPa}$ strength and suggested to use $\mathrm{CO}_{2}$ emission amount $352 \mathrm{~kg}$ for recycled type of steel with $420 \mathrm{MPa}$ strength. Paya et al. [56] suggested to use $3010 \mathrm{~kg}$ for the $\mathrm{CO}_{2}$ emission amount of steel and the $\mathrm{CO}_{2}$ emission amount $143.48 \mathrm{~kg}$ for the concrete (HA-30) that has $30 \mathrm{MPa}$ strength. 
Table 4. Unit amounts of $\mathrm{CO}_{2}$ emissions of structural materials.

\begin{tabular}{ccccc}
\hline Material & Class & Analysis 1 (A1) & Analysis 2 (A2) & Analysis 3 (A3) \\
\hline Concrete & C30 & 376 & 143.48 & 143.48 \\
Steel & S420 & 352 & 3010 & 352 \\
\hline
\end{tabular}

\section{Result and Discussion}

The efficiency of HS was checked by comparing with flower pollination algorithm (FPA) developed by Yang [57] for several cases of optimization by using the first objective function. Then, the parametric analyses are presented by employing HS, since it was effective in most of the cases that minimize objective function, as seen in the comparison cases given as Table 5 .

Table 5. Comparison of harmony search (HS) and flower pollination algorithm (FPA).

\begin{tabular}{|c|c|c|c|c|c|c|c|c|c|c|c|c|}
\hline & $H(m)$ & $\gamma\left(k N / m^{3}\right)$ & $\Phi\left(^{\circ}\right)$ & $q$ & $C_{c}(\$)$ & $C_{s}(\$)$ & $X_{1}(m)$ & $X_{2}(m)$ & $X_{3}(m)$ & $X_{4}(m)$ & $X_{5}(m)$ & $f_{\text {cost }}(\$)$ \\
\hline \multirow{7}{*}{ HS } & 3 & 18 & 30 & 0 & 50 & 700 & 1.85 & 0.00 & 0.20 & 0.30 & 0.30 & 91.27 \\
\hline & 4 & 18 & 30 & 0 & 50 & 700 & 2.52 & 0.00 & 0.20 & 0.31 & 0.30 & 149.08 \\
\hline & 5 & 18 & 30 & 0 & 50 & 700 & 3.13 & 0.00 & 0.20 & 0.42 & 0.30 & 238.51 \\
\hline & 6 & 18 & 30 & 0 & 50 & 700 & 3.65 & 0.83 & 0.20 & 0.59 & 0.33 & 361.24 \\
\hline & 7 & 18 & 30 & 0 & 50 & 700 & 4.25 & 0.97 & 0.20 & 0.73 & 0.40 & 517.07 \\
\hline & 8 & 18 & 30 & 0 & 50 & 700 & 4.85 & 1.11 & 0.20 & 0.89 & 0.48 & 708.39 \\
\hline & 9 & 18 & 30 & 0 & 50 & 700 & 5.42 & 1.26 & 0.20 & 1.08 & 0.56 & 937.74 \\
\hline \multirow{7}{*}{ FPA } & 3 & 18 & 30 & 0 & 50 & 700 & 1.85 & 0.00 & 0.20 & 0.30 & 0.30 & 91.27 \\
\hline & 4 & 18 & 30 & 0 & 50 & 700 & 2.52 & 0.00 & 0.20 & 0.31 & 0.30 & 149.08 \\
\hline & 5 & 18 & 30 & 0 & 50 & 700 & 3.13 & 0.00 & 0.20 & 0.42 & 0.30 & 238.51 \\
\hline & 6 & 18 & 30 & 0 & 50 & 700 & 3.76 & 0.00 & 0.20 & 0.54 & 0.38 & 363.10 \\
\hline & 7 & 18 & 30 & 0 & 50 & 700 & 4.39 & 0.00 & 0.20 & 0.67 & 0.46 & 521.69 \\
\hline & 8 & 18 & 30 & 0 & 50 & 700 & 4.85 & 1.12 & 0.20 & 0.88 & 0.48 & 708.41 \\
\hline & 9 & 18 & 30 & 0 & 50 & 700 & 5.42 & 1.25 & 0.20 & 1.07 & 0.56 & 937.68 \\
\hline
\end{tabular}

Based on the details mentioned in the parametric analysis case, 43,750 numerical analyses were conducted. The results of the analyses were divided into three sections according to the solutions of objective functions. The first case included the results of objective function 1 to discuss the influence of costs on the design. The second case included the results of objective function 2 to discuss the influence of $\mathrm{CO}_{2}$ emission on the design. The third case included the results of objective function 3 to discuss the integrated influence of cost and $\mathrm{CO}_{2}$ emission. Cases 2 and 3 were divided into three divisions to examine the effects of the change of the amount of $\mathrm{CO}_{2}$ emission. The results of the solutions of three objective functions are illustrated with graph systems. The notion $C_{t}$ represents the total cost of the retaining wall for unit width, $h$ is the excavation depth, $H$ is the total length of the retaining wall, $C_{c}$ is the unit cost of the concrete for per $\mathrm{m}^{3}, C_{s}$ is the unit cost of the steel for per $\mathrm{kg}$ for all the illustrated graphs. Besides this, the shear strength angle of the soil formation that the wall penetrates was selected as constant in all the conducted cases $\left(\Phi=30^{\circ}\right)$.

Case 1: The relationship between the minimum cost and attainment of appropriate dimensions of retaining walls were investigated, considering the change of the excavation depth, the costs of materials, the unit weight of soil, and the surcharge load. Equation (11) was used to focus on the minimization of only the cost of the cases investigated in Case 1.

In Figure 2, the results of the analyses are given depending on the change in the cost of the concrete, while the cost of the steel is selected as a constant value (\$700). 


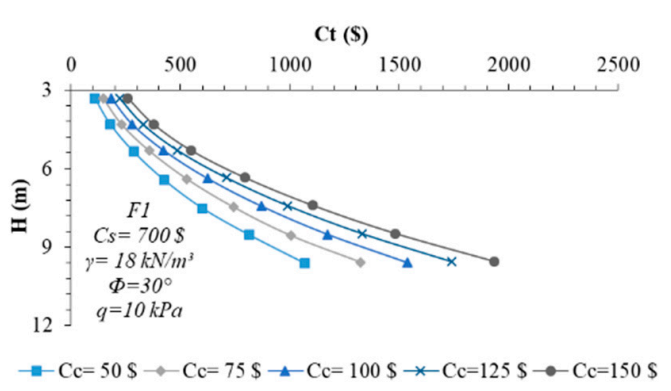

(a)

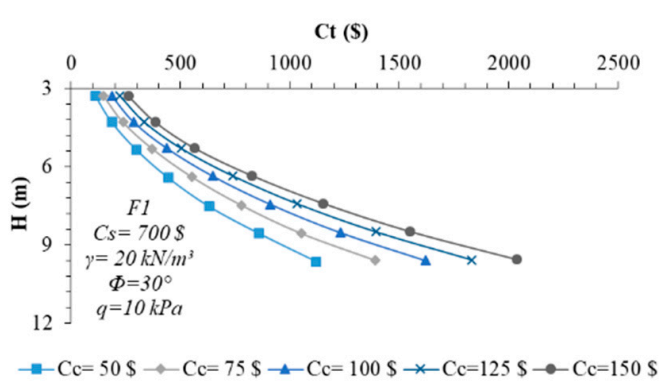

(c)

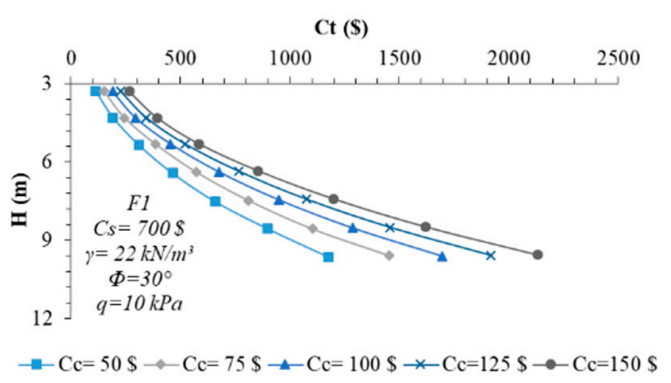

(e)

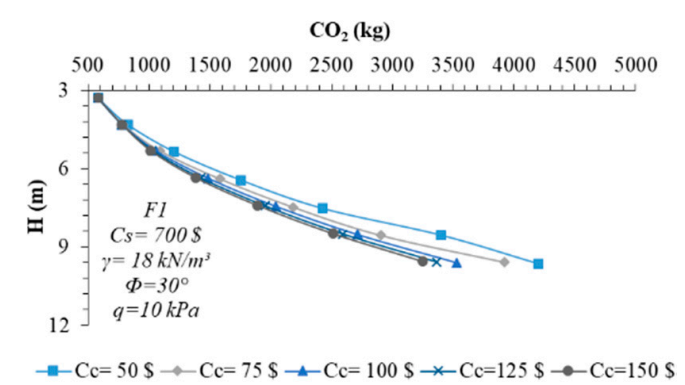

(b)

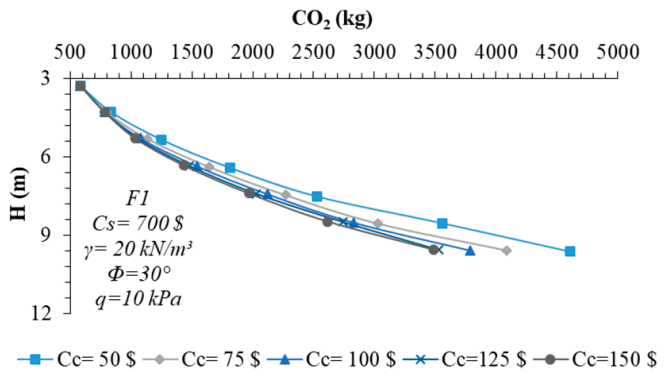

(d)

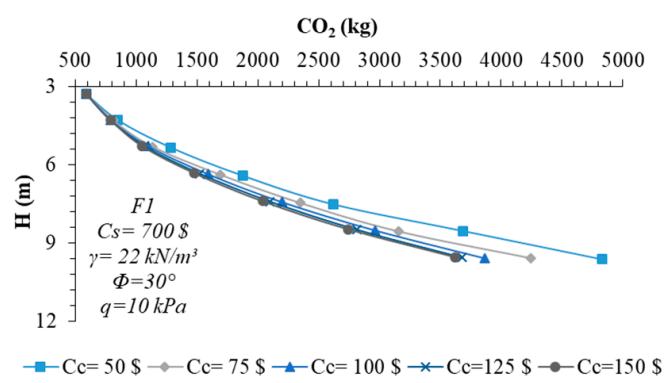

$(\mathbf{f})$

Figure 2. The change of total cost and $\mathrm{CO}_{2}$ emission values against the change of unit cost of concrete and the excavation depth for the optimum values according to F1.

In Figure 2a, the change in total cost of the retaining wall construction is given against the height of the retaining wall and the increase of the unit cost of the concrete. In Figure $2 b$, the change of the total $\mathrm{CO}_{2}$ emission of the retaining wall is given against the height of the retaining wall and the increase of the unit cost of the concrete. In this case, the calculation of the $\mathrm{CO}_{2}$ emission of the retaining wall was done according to A1 in Table 4 . The unit weight of the soil medium was assumed to be $18 \mathrm{kN} / \mathrm{m}^{3}$ and the amount of the surcharge was selected to be $10 \mathrm{kPa}$ for both Figure $2 \mathrm{a}, \mathrm{b}$. The total height of the wall increased directly proportional to the increase of the excavation depth, as expected. The increase of the height of the wall system led to a rise in the total costs. Similarly, the increase of the unit cost of the construction materials caused an increase in the total costs. The total cost of the wall system was calculated to be $\$ 108$ and $\$ 1070$ for 3 and 9 m excavation depths, respectively, if the unit cost of the concrete was selected as $\$ 50$. The increase ratio of the total cost of the retaining wall in such a case that $C_{c}=\$ 50$ perceived an increase of $890 \%$ against the increase of the excavation depth $9 \mathrm{~m}$ from $3 \mathrm{~m}$. In addition to these, if $C_{c}$ is selected as $\$ 150$, the total cost of the wall is $\$ 260$ and $\$ 1933$ for 3 and $9 \mathrm{~m}$ excavation depth, respectively. This condition shows that the increase ratio of the total cost is calculated approximately $650 \%$. Therefore, it can be said that an increase of the concrete costs leads to a reduction in the rate of increase of the total cost, however the total height of the wall is increased. The increase of the unit cost of concrete from $\$ 50$ to $\$ 150$ leads to a rise in the total cost from $\$ 108$ to 
$\$ 260$ at $3 \mathrm{~m}$ excavation depth. On the other hand, the increase of the unit cost of the concrete from $\$ 50$ to $\$ 150$ leads to a rise in the total cost from $\$ 1070$ to $\$ 3251$ at $9 \mathrm{~m}$ excavation depth. This situation presents the cost increase effect of the same depth. The increase of the unit costs increases the effect rate on the increase of total cost significantly. In addition to all these, the change in the unit cost of the concrete does not form any significant difference between the total heights of the wall.

In Figure $2 b$, it is clear that the change in the concrete costs did not create an apparent change in the $\mathrm{CO}_{2}$ emission. This situation is related to the change tendency of wall dimensions. The increase in the wall height caused an increase in the emission values, but this increase rate did not happen at the same as the increase that happened to the total cost. Vice versa, the increase of the dimensions by the decrease of the concrete costs increased the $\mathrm{CO}_{2}$ emission by a slight value, as expected. The increase of the excavation depth led to a rise in the $\mathrm{CO}_{2}$ emission values by approximately $700 \%$ for $\mathrm{C}_{\mathrm{c}}=\$ 50$ and $745 \%$ for $C_{c}=\$ 150$, respectively. This means that at the same excavation depth, the rise rate of the $\mathrm{CO}_{2}$ emission values is not bigger than the rates calculated for the total cost. Figure 2c,e illustrate the influence of the change of the unit weight change and material cost change in the total cost.

Figure $2 \mathrm{~d}$, f illustrate the changes in $\mathrm{CO}_{2}$ emission values against the change of unit weight of soil and the cost of materials. In Figure $2 \mathrm{c}$, the unit weight of the soil is $20 \mathrm{kN} / \mathrm{m}^{3}$ and in Figure $2 \mathrm{e}$, the unit weight of the soil is $22 \mathrm{kN} / \mathrm{m}^{3}$. The comparison of Figure $2 \mathrm{a}, \mathrm{c}, \mathrm{e}$ reveals the same increase tendency against the increase of excavation depth through the change of the costs of materials and unit weight of the soil. In such a case that the increase of the unit weight of the soil begins to reach 18 to $22 \mathrm{kN} / \mathrm{m}^{3}$, this leads to an increase in the total cost of the system (\$1932 to \$2131) at a depth of excavation of $9 \mathrm{~m}$. Therefore, the increase of soil unit weight leads to an increase in the total cost of a maximum of $10 \%$.

The influence of the change in soil unit weight was also studied in the control of $\mathrm{CO}_{2}$ emission values. The discussion of Figure $2 \mathrm{~b}, \mathrm{~d}, \mathrm{f}$ represents the $\mathrm{CO}_{2}$ emission change that happened, at a maximum of $15 \%$ at $9 \mathrm{~m}$ excavation depth.

The effect of the change of unit weight of soil was also investigated in Figure 3 for different situations. The absence of surcharge load was considered and the unit costs of concrete and steel were selected as constant values $\left(C_{c}=\$ 50\right.$ and $\left.C_{s}=\$ 700\right)$.

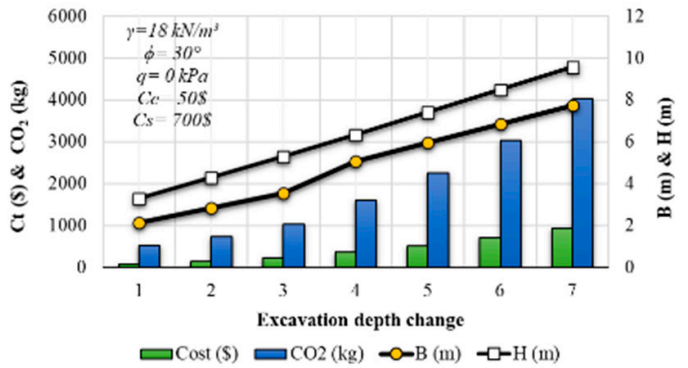

(a)

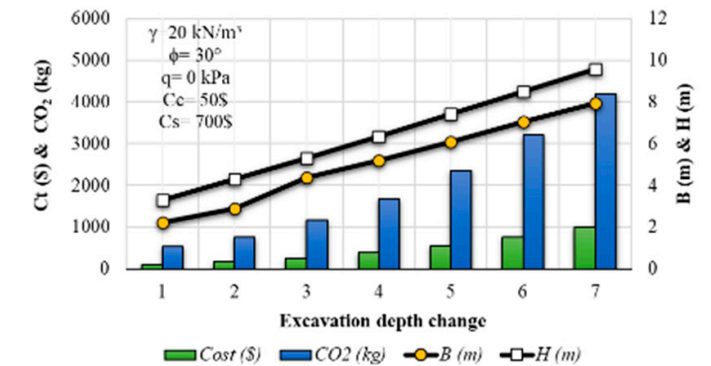

(b)

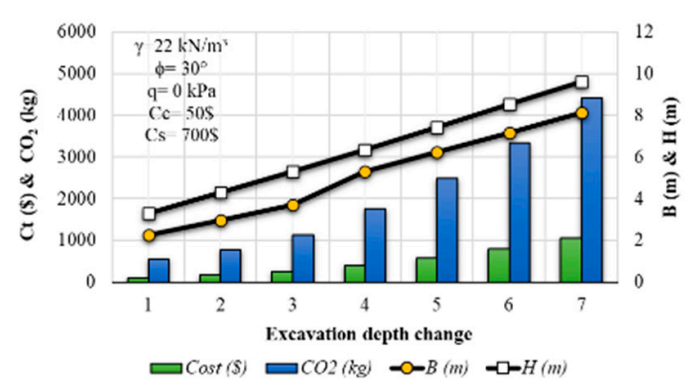

(c)

Figure 3. The change of total cost and $\mathrm{CO}_{2}$ emission values against the change of wall dimensions and excavation depth (a) $\gamma=18 \mathrm{kN} / \mathrm{m}^{3}$ (b) $\gamma=20 \mathrm{kN} / \mathrm{m}^{3}$ (c) $\gamma=22 \mathrm{kN} / \mathrm{m}^{3}$. 
The multi-variant interaction between the components of the cost minimization problem was investigated completely in the subdivisions of Figure 3. The change in the retaining wall dimensions was also evaluated. The changes in total cost and $\mathrm{CO}_{2}$ emissions are shown with columns and the change in the dimensions of the wall is shown with lines in Figure 3. The change in the excavation depth was taken into account in the horizontal axis of the graphs. The numbers that are beginning from 1 represent the additional excavation steps. The excavation depths that were changing beginning from 3 to $9 \mathrm{~m}$ by $1 \mathrm{~m}$ increments are represented by the numbers from 1 to 7 , respectively. The dimensions of the wall system were not changed noteworthily based on the change of the unit weight. The comparison of Figure 3a,c shows the relative change of the $\mathrm{CO}_{2}$ emission values against the change of excavation depth. It is clear to see that the increase trends of entire parameters like $C_{t}, \mathrm{CO}_{2}$ emission, $B$, and $H$ were similar. The inclination of the width and height change lines was same for all the conditions investigated at Figure 3.

In Figure 4, the effects of surcharge load change are investigated in relation to the change in wall dimensions, total cost, and $\mathrm{CO}_{2}$ emission. The unit weight of the soil was assumed to be constant at $20 \mathrm{kN} / \mathrm{m}^{3}$ and the costs of the materials were also taken as constant values of $C_{c}=\$ 50$ and $C_{s}=\$ 700$. The surcharge load was selected to be $0,5,10,15,20 \mathrm{kPa}$ and abbreviated with the numbers 1, 2, 3, 4, 5, respectively, at the horizontal axes.

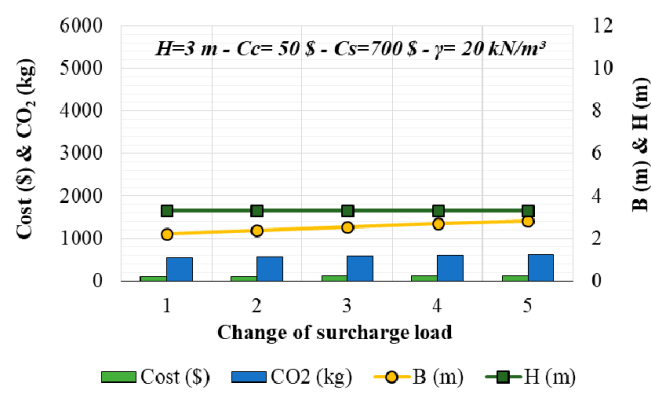

(a)

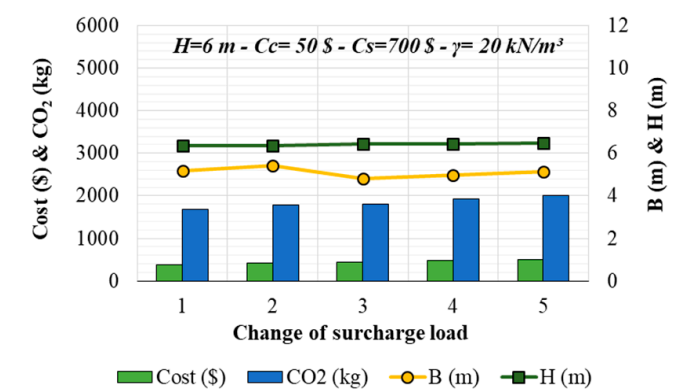

(b)

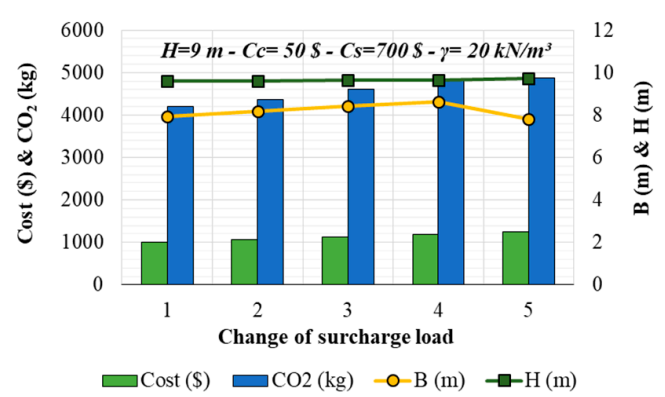

(c)

Figure 4. The change of total cost and $\mathrm{CO}_{2}$ emission values against the change of wall dimensions and the amount of surcharge load (a) $\mathrm{H}=3 \mathrm{~m},(\mathbf{b}) \mathrm{H}=6 \mathrm{~m}$, (c) $\mathrm{H}=9 \mathrm{~m}$.

The change in surcharge loading amount affects both the total cost and $\mathrm{CO}_{2}$ emission values. The increase in the surcharge magnitude raises both cost and emission, especially with an increasing depth of excavation. The effect of the surcharge load increase is smaller for the relatively smaller excavation depths based on the small change of dimensions caused by the surcharge increase. It will be clear to say that the effect of excavation depth is dominant than the change of surcharge loading amount on the design and gas emission of the structure.

In Figure 5, the excavation depth was assumed to be constant at $\mathrm{H}=6 \mathrm{~m}$ for the subdivisions $\mathrm{a}$ and $\mathrm{b}, \mathrm{H}=9 \mathrm{~m}$ for the subdivisions $\mathrm{c}$ and $\mathrm{d}$. The soil medium characteristics were also selected to be constant, the internal friction angle was $30^{\circ}$ and the unit weight of the soil was $20 \mathrm{kN} / \mathrm{m}^{3}$. The aim of the illustration was to control the effects of the change of the material costs on the total cost and $\mathrm{CO}_{2}$ 
emission evaluation. In Figure 5a, the unit cost of steel was selected to be $\$ 700$ as a constant value to control the effect of the unit cost of concrete on the design and emission. The unit cost of the concrete was chosen to be $\$ 50, \$ 75, \$ 100, \$ 125, \$ 150$. Also, the change in the surcharge loading is shown in Figure 5. If the absence of the surcharge load was evaluated, $89 \%$ change of total cost was obtained between the upper $\left(C_{t}=\$ 723\right)$ and lower limits $\left(C_{t}=\$ 382\right)$ of the $C_{c}$. The increase in the concrete unit cost had a significant increasing effect on the total cost. On the contrary, the increase in the concrete costs decreased the $\mathrm{CO}_{2}$ emission by approximately $24 \%$ between the lower $\left(\mathrm{CO}_{2}=1673 \mathrm{~kg}\right)$ and upper $\left(\mathrm{CO}_{2}=1271 \mathrm{~kg}\right)$ limits of $\mathrm{C}_{\mathrm{c}}$. The decrease in the $\mathrm{CO}_{2}$ emissions depends on the reduction of the dimensions of the wall system. The optimization-based design procedure makes it possible to narrow the section and therefore the amount of concrete used decreases, but in order to ensure structural requirements, the amount of steel required increases. The decrease of the width of the foundation base was calculated to be 5.18 and $4.29 \mathrm{~m}$ for the lower and upper limits of $C_{c}$, respectively. In this case, the total difference that was caused by the increase in $C_{c}$ can be calculated as $17 \%$ for the change of base width. The relative change in the wall height was smaller than the change of the base width and can be calculated as approximately $1 \%$. Therefore, there is a decrease in the total cost while an increase in the unit cost of the concrete occurs, and it is possible by the increase of the reinforcing bar number or diameter. This situation makes it possible to narrow the base width. This condition leads to gaining an eco-friendly design. In such a case that the surcharge load is $20 \mathrm{kPa}$, the total cost of the system has been increased $83 \%$ and the $\mathrm{CO}_{2}$ emission, the width of the foundation, and the height of the wall has been decreased $21 \%, 3 \%$, and $1.6 \%$ respectively.

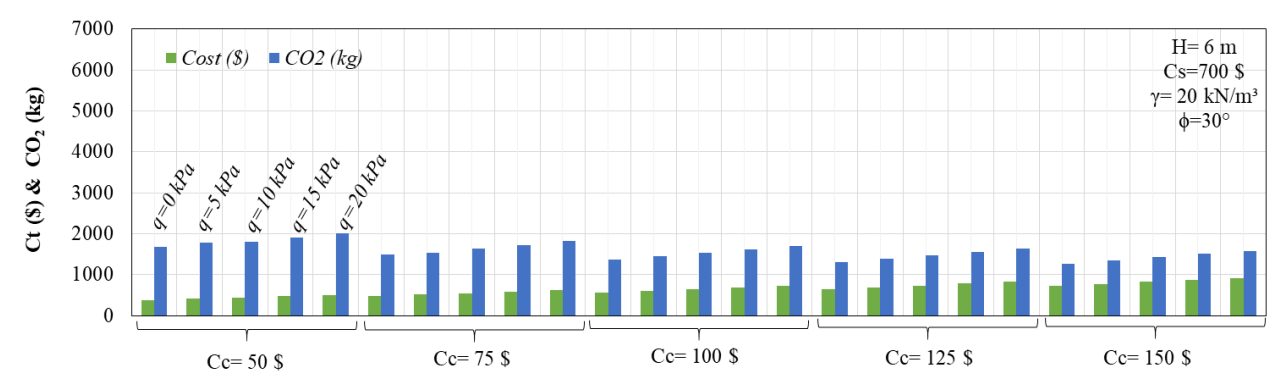

(a)

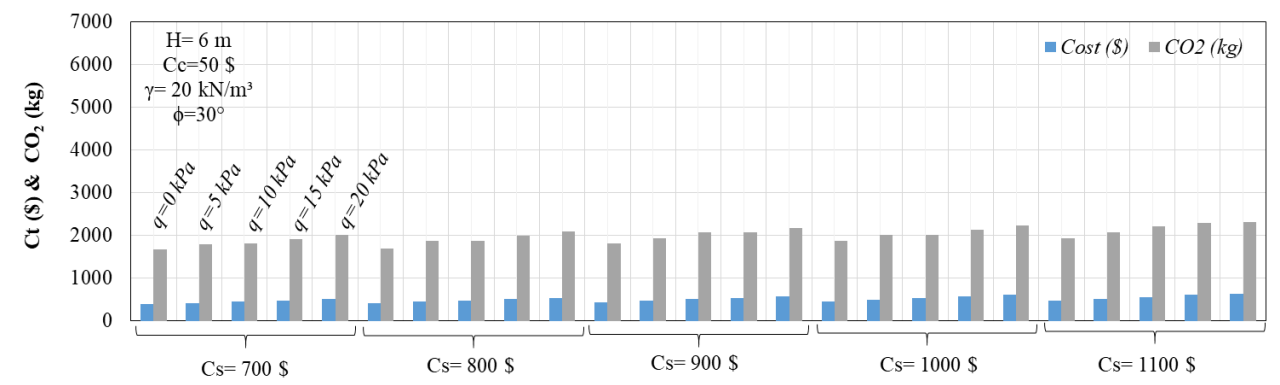

(b)

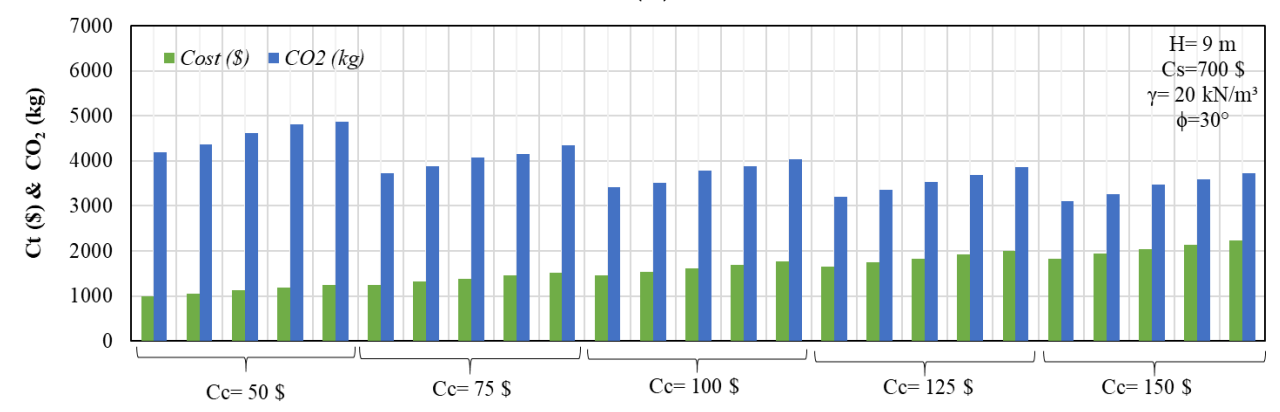

(c)

Figure 5. Cont. 


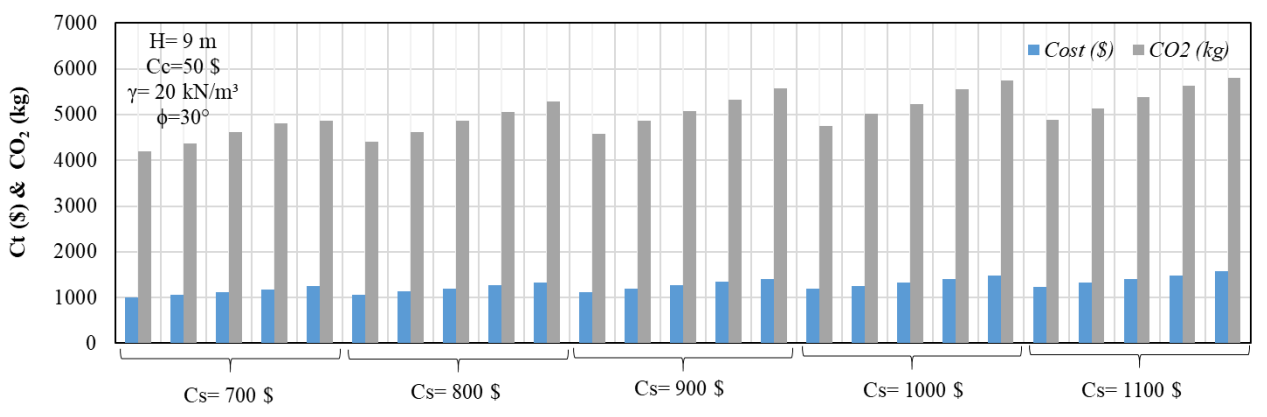

(d)

Figure 5. The change of total cost and $\mathrm{CO}_{2}$ emission against the change in unit cost of structural materials. (a) The change of $\mathrm{C}_{\mathrm{c}}$ at $\mathrm{H}=6 \mathrm{~m}$, (b) The change of $\mathrm{C}_{\mathrm{s}}$ at $\mathrm{H}=6 \mathrm{~m}$, (c) The change of $\mathrm{C}_{\mathrm{c}}$ at $\mathrm{H}=9 \mathrm{~m},(\mathbf{d})$ The change of $\mathrm{C}_{\mathrm{s}}$ at $\mathrm{H}=9 \mathrm{~m}$.

In addition, hand calculations were conducted to control the performance of the applied optimization technique. H was assumed to be $6 \mathrm{~m}$, the unit weight of the soil was $20 \mathrm{kN} / \mathrm{m}^{3}$, the internal friction angle was $30^{\circ}$, and the absence of the surcharge was envisaged. In these circumstances, if the optimization analysis is conducted for $C_{c}=50 \$$ and $C_{s}=700 \$$, the width of the base is determined as $5.18 \mathrm{~m}$ and the height of the wall is calculated as $6.35 \mathrm{~m}$, the total cost of the system is obtained as $382.51 \$$ and the $\mathrm{CO}_{2}$ emission is acquired as $1673.41 \mathrm{~kg}$. If same analysis is performed and $\mathrm{C}_{\mathrm{c}}$ is raised to the amount of $150 \$$, the width of the base is determined as $4.29 \mathrm{~m}$ and the height of the wall is calculated as $6.30 \mathrm{~m}$, the total cost of the system is obtained as $723 \$$ and the $\mathrm{CO}_{2}$ emission is acquired as $1271 \mathrm{~kg}$. The optimum design variable results found according to $C_{c}=50 \$$ were used to calculate the amount of the total cost and $\mathrm{CO}_{2}$ emission if the cost of the concrete per unit weight was raised to $150 \$$. In that situation, the total cost of the system was raised to $767.17 \$$ and the $\mathrm{CO}_{2}$ emission was determined as $1661.10 \mathrm{~kg}$. The relative cost and emission difference percentage occurred between the results that were not the optimum of the exact design variables and optimum results done according to the exact values of parameters were determined as $6.1 \%$ and $30.7 \%$, respectively. This comparison was done to virtualize a traditional design case by using the dimensions and reinforcements of optimum results of another parametric investigation providing geotechnical and structural state limits.

Another comparison approach was applied by changing the excavation depth of $9 \mathrm{~m}$. In that condition, if the optimization analysis is conducted for $C_{c}=50 \$$ and $C_{s}=700 \$$, the width of the base is determined to be $7.94 \mathrm{~m}$, the height of the wall is calculated as $9.58 \mathrm{~m}$ and the total cost of the system is obtained as 997 \$ and the $\mathrm{CO}_{2}$ emission is acquired as $4198 \mathrm{~kg}$. If $\mathrm{C}_{\mathrm{c}}$ is raised to the amount of $150 \$$, the width of the base is determined to be $8.26 \mathrm{~m}$ and the height of the wall is calculated to be $9.64 \mathrm{~m}$, the total cost of the system is obtained as $1240 \$$, and the $\mathrm{CO}_{2}$ emission is acquired as $4892 \mathrm{~kg}$ for optimum results. The virtualized hand calculations based on the traditional pre-design methods [33] were applied to the foreseen problem. As a result, the width of the base was determined to be $7.95 \mathrm{~m}$ and the total height of the wall was calculated as $9.58 \mathrm{~m}$. Back analysis was conducted for the obtained dimensions of the wall to determine the total cost and the $\mathrm{CO}_{2}$ emission. According to the hand calculations and back analysis, the required total cost and generated $\mathrm{CO}_{2}$ emission was attained as $1947.37 \$$ and $4152.74 \mathrm{~kg}$, respectively. This relative difference is especially revealing of the significance of the application of optimization algorithms for the design problem of retaining wall systems to ensure stable and cost-effective design. However, the amount of the $\mathrm{CO}_{2}$ emission determined by optimization analysis was bigger than the results of the traditional analysis. Therefore, the necessity of usage of objective function related to the minimization of $\mathrm{CO}_{2}$ emission is born.

Besides this, the relative change of the wall dimensions is smaller than $\mathrm{q}=0$ for $\mathrm{q}=20 \mathrm{kPa}$, but it seems to be a confusing situation that the change of the $\mathrm{CO}_{2}$ emission value is decreased based on the increase of the unit cost of the concrete if the cost of the steel remains constant at the lower limit of the envisaged values. This phenomenon represents the advantage of the application of optimization 
techniques to minimize both the cost and $\mathrm{CO}_{2}$ emissions by decreasing the dimensions of the wall. In Figure $5 \mathrm{~b}$, the change in $\mathrm{C}_{\mathrm{s}}$ was evaluated by assuming the unit cost of the concrete as a constant value at $50 \$$ and $C_{s}$ was selected to be $\$ 700, \$ 800, \$ 900, \$ 1000$, and $\$ 1100$. The increase in the unit cost of the steel by $57 \%$ led to an increase in the total cost, the $\mathrm{CO}_{2}$ emission, the width of the base, and the height of the wall by $23 \%, 16 \%, 4 \%$, and $0.8 \%$, respectively. These percentages were obtained according to the upper (1100\$) and lower (700\$) boundaries of envisaged steel costs and the absence of the surcharge was taken into consideration. The increase of the surcharge magnitude to $20 \mathrm{kPa}$ led to a change in the difference ratio of steel cost effect of the design. The increase of the unit cost of the steel by $57 \%$ led to an increase in the total cost, the $\mathrm{CO}_{2}$ emission, the width of the base and the height of the wall by $26.5 \%, 14 \%, 2 \%$, and $0.8 \%$, respectively.

The geometry of the wall is more changeable depending on the change in the unit cost of the concrete rather than the change in the unit cost of the steel. In Figure $5 c, d$, the increase of the excavation depth was also investigated by the comparison with Figure $5 \mathrm{a}, \mathrm{b}$ against the change of unit cost of concrete and steel, respectively. In such a case that the excavation depth is $9 \mathrm{~m}$, the effect of the change of $C_{c}$ was investigated in Figure $5 c$ and the change of $C_{s}$ was investigated in Figure $5 d$. The increase in the unit cost of the concrete by $200 \%$ for the condition that $\mathrm{H}=9 \mathrm{~m}$ and $\mathrm{q}=0 \mathrm{kPa}$ led to an increase in the total cost, the $\mathrm{CO}_{2}$ emission, the width of the base, and the height of the wall by $24 \%, 16.5 \%, 4 \%$, and $0.5 \%$, respectively (Figure $5 \mathrm{c}$ ). The decrease of $\mathrm{CO}_{2}$ emission that happens when $\mathrm{H}=6 \mathrm{~m}$ was not available for the case with $\mathrm{H}=9 \mathrm{~m}$. This may be the result of the unattainable static and geotechnical equilibrium and compatibility conditions by the use of the previously calculated wall section.

Besides, the increase of the unit cost of the steel by $57 \%$ for the condition that $\mathrm{H}=9 \mathrm{~m}$ and $\mathrm{q}=20 \mathrm{kPa}$ led to an increase in the total cost, the $\mathrm{CO}_{2}$ emissions, the width of the base, and the height of the wall by $26 \%, 19 \%, 14 \%$, and $0.05 \%$, respectively. The increase of the wall foundation base width caused an increase in the total costs and $\mathrm{CO}_{2}$ emission amount, as expected. The increment rate was relatively bigger for bigger amounts of surcharge. However, the increase of the cost and $\mathrm{CO}_{2}$ emission occurs due to the change of the foundation base width rather than the change of the height of the wall. The increase of the base width may be related to the requirement of the attainment of the safety caused by the base pressure. Therefore, it is possible to express an opinion that the equilibrium of base pressure constitutes the critical controlling state of the walls based on the dominant soil profile at the project site.

In addition, hand calculations were also conducted according to the change in the steel cost change, to discuss the usage of optimization algorithm effectiveness. H was assumed to be $6 \mathrm{~m}$, the unit weight of the soil was $20 \mathrm{kN} / \mathrm{m}^{3}$, the internal friction angle was $30^{\circ}$, and the absence of the surcharge was envisaged. In these circumstances, if the optimization analysis is conducted for $C_{c}=50 \$$ and $C_{s}=700 \$$, the width of the base is determined as $5.18 \mathrm{~m}$, the height of the wall is calculated as $6.35 \mathrm{~m}$, the total cost of the system is obtained as $382.51 \$$, and the $\mathrm{CO}_{2}$ emission is acquired as $1673.41 \mathrm{~kg}$. If same analysis is performed if $C_{s}$ is raised to the amount of $1100 \$$, the width of the base is determined as $5.40 \mathrm{~m}$, the height of the wall is calculated as $6.38 \mathrm{~m}$, the total cost of the system is obtained as $472 \$$, and the $\mathrm{CO}_{2}$ emission is acquired as $1936 \mathrm{~kg}$. The hand calculations based on the traditional pre-design methods [33] were applied to the foreseen problem. As a result, the width of the base was determined to be the same as the optimization analysis conducted for $C_{c}=50 \$, C s=700 \$$ case. In that case, the total cost and the $\mathrm{CO}_{2}$ emission were determined. According to the hand calculations, the required total cost and generated $\mathrm{CO}_{2}$ emission were attained as $425.38 \$$ and $1766.92 \mathrm{~kg}$, respectively. Then, the increase in the excavation depth was also investigated by performing optimization analysis $(\mathrm{H}=9 \mathrm{~m})$ and the total cost of the system was obtained as 997.21 \$ and the $\mathrm{CO}_{2}$ emission is acquired as $4198.35 \mathrm{~kg}$. Consequently, according to hand calculations, it was found that the width of the base was $8.04 \mathrm{~m}$, the height of the wall was $9.58 \mathrm{~m}$, the total cost was $1099.35 \$$ and $\mathrm{CO}_{2}$ emission amount was $4152.74 \mathrm{~kg}$. These discussions reflect the requirement of the usage of the optimization techniques while design to obtain stability and sustainability together. 
Case 2: This case was prepared to give priority to the minimize $\mathrm{CO}_{2}$ emission amount by using a different objective function. The aim was to evaluate the lower amount of gas emission rather than cost minimization. The relationship between the minimum amount of $\mathrm{CO}_{2}$ emission and attainment of appropriate dimensions of retaining walls was investigated considering the change of the excavation depth, the costs of materials, the unit weight of soil and the surcharge load. Equation (12) has been used to focus only on the minimization of emission for the cases investigated in Case 2.

On the other hand, the relationship between the $\mathrm{CO}_{2}$ emissions and design was evaluated by the selection of different $\mathrm{CO}_{2}$ emission amounts for both steel and concrete. Three different material cost couples were selected for analysis, abbreviated as A1, A2, and A3 (Table 4). Figure 6 is illustrated to represent the relationship between cost and dimensions against the minimization process of $\mathrm{CO}_{2}$ emissions. In Figure 6, the unit cost of the concrete was 50 , the unit cost of the steel was $700 \$$, the unit weight of the soil was $20 \mathrm{kN} / \mathrm{m}^{3}$, the internal friction angle of the soil was $30^{\circ}$, and the absence of the surcharge load was evaluated to compare the difference of envisaged different analyses such as A1, $\mathrm{A} 2$, and $\mathrm{A} 3$.

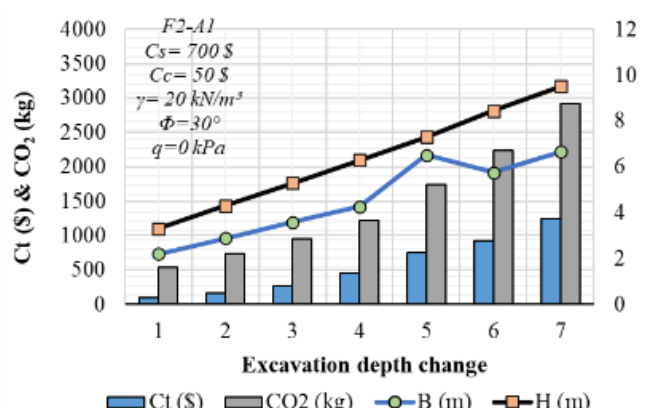

\begin{tabular}{|c|c|c|c|c|c|c|c|c|c|}
\hline $\mathrm{X} 1(\mathrm{~m})$ & X2 (m) & X3 (m) & X4 (m) & X5 (m) & $\mathrm{Ct}(\$)$ & $\mathrm{CO} 2(\mathrm{~kg})$ & $\mathrm{h}(\mathrm{m})$ & $\mathrm{B}(\mathrm{m})$ & $\mathrm{H}(\mathrm{m})$ \\
\hline 1,91 & 0,00 & 0,20 & 0,30 & 0,30 & 94,13 & 542,59 & 3 & 2,21 & 3,30 \\
\hline 2,59 & 0,00 & 0,20 & 0,30 & 0,30 & 156,35 & 733,83 & 4 & 2,89 & 4,30 \\
\hline 3,28 & 0,00 & 0,20 & 0,30 & 0,30 & 264,12 & 948,00 & 5 & 3,58 & 5,30 \\
\hline 3,97 & 0,00 & 0,20 & 0,30 & 0,31 & 456,22 & 1213,17 & 6 & 4,27 & 6,31 \\
\hline 4,54 & 1,63 & 0,20 & 0,35 & 0,30 & 744,11 & 1736,63 & 7 & 6,52 & 7,30 \\
\hline 5,34 & 0,00 & 0,20 & 0,42 & 0,45 & 929,59 & 2234,02 & 8 & 5,76 & 8,45 \\
\hline 6,00 & 0,16 & 0,20 & 0,49 & 0,52 & 1243,83 & 2919,73 & 9 & 6,65 & 9,52 \\
\hline
\end{tabular}

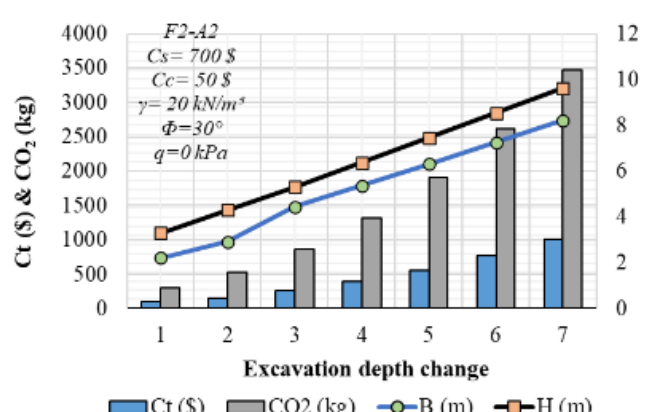

(a)

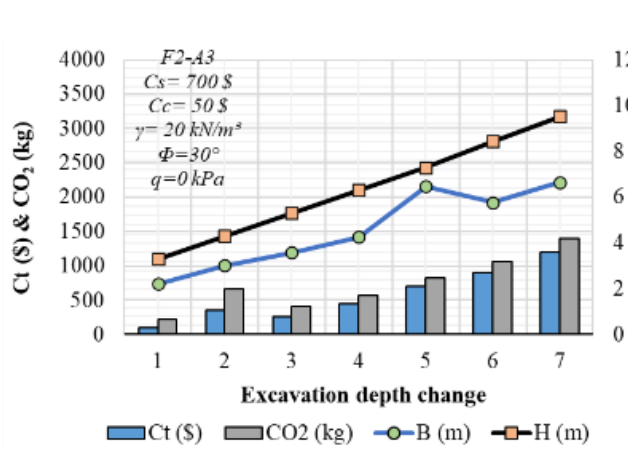

\begin{tabular}{|c|c|c|c|c|c|c|c|c|c|}
\hline $\mathrm{X} 1(\mathrm{~m})$ & X2 (m) & X3 (m) & X4 (m) & X5 (m) & $\mathrm{Ct}(\$)$ & $\mathrm{CO} 2(\mathrm{~kg})$ & $\mathrm{h}(\mathrm{m})$ & $\mathrm{B}(\mathrm{m})$ & $\mathrm{H}(\mathrm{m})$ \\
\hline 1,91 & 0,00 & 0,20 & 0,30 & 0,30 & 94,13 & 303,82 & 3 & 2,21 & 3,30 \\
\hline 2,54 & 0,00 & 0,20 & 0,39 & 0,30 & 157,24 & 529,70 & 4 & 2,92 & 4,30 \\
\hline 3,04 & 0,82 & 0,20 & 0,58 & 0,30 & 255,58 & 865,02 & 5 & 4,44 & 5,30 \\
\hline 3,64 & 0,98 & 0,20 & 0,75 & 0,37 & 388,29 & 1322,43 & 6 & 5,37 & 6,37 \\
\hline 4,22 & 1,14 & 0,20 & 0,96 & 0,45 & 557,68 & 1903,70 & 7 & 6,32 & 7,45 \\
\hline 4,79 & 1,28 & 0,20 & 1,17 & 0,53 & 764,41 & 2618,92 & 8 & 7,25 & 8,53 \\
\hline 5,37 & 1,47 & 0,20 & 1,39 & 0,63 & 1013,23 & 3476,75 & 9 & 8,22 & 9,63 \\
\hline
\end{tabular}

(b)

\begin{tabular}{|c|c|c|c|c|c|c|c|c|c|}
\hline $\mathrm{X} 1(\mathrm{~m})$ & $\mathrm{X} 2(\mathrm{~m})$ & X3 (m) & $\mathrm{X} 4(\mathrm{~m})$ & $\mathrm{X} 5(\mathrm{~m})$ & $\mathrm{Ct}(\$)$ & $\mathrm{CO} 2(\mathrm{~kg})$ & $\mathrm{h}(\mathrm{m})$ & $B(m)$ & $\mathrm{H}(\mathrm{m})$ \\
\hline 1,91 & 0,00 & 0,20 & 0,30 & 0,30 & 94,13 & 214,38 & 3 & 2,21 & 3,30 \\
\hline 2,62 & 0,00 & 0,20 & 0,30 & 0,30 & 156,90 & 663,32 & 4 & 2,92 & 4,30 \\
\hline 3,28 & 0,00 & 0,20 & 0,30 & 0,30 & 264,12 & 407,76 & 5 & 3,58 & 5,30 \\
\hline 3,96 & 0,00 & 0,20 & 0,31 & 0,31 & 450,80 & 561,06 & 6 & 4,27 & 6,31 \\
\hline 4,51 & 1,56 & 0,20 & 0,40 & 0,30 & 695,67 & 828,00 & 7 & 6,47 & 7,30 \\
\hline 5,32 & 0,00 & 0,20 & 0,45 & 0,45 & 897,38 & 1060,92 & 8 & 5,76 & 8,45 \\
\hline 5,98 & 0,15 & 0,20 & 0,53 & 0,52 & 1194,59 & 1395,10 & 9 & 6,65 & 9,52 \\
\hline
\end{tabular}

(c)

Figure 6. The change in $\mathrm{CO}_{2}$ emissions and total cost against wall dimensions and the excavation depth $\left(\mathrm{C}_{\mathrm{c}}=50 \$, \mathrm{C}_{\mathrm{s}}=700\right.$ \$, q = $\left.0 \mathrm{kPa}\right)$ (a) Analysis 1, (b) Analysis 2, (c) Analysis 3.

The numbers given on the horizontal axis represent the lineup of the excavation depth, beginning from the smallest value. The detailed expressions of dimensions of the obtained cost and optimum emission values are also given in additional tables next to the graphs. The increases in dimensions of 
the wall, cost, and $\mathrm{CO}_{2}$ emission occur according to the rise in the excavation depth. According to the given graphs and tables, the comparison of the analyses A1 (Figure 6a) and A3 (Figure 6c) reflects the effects of the increase of the concrete emission. The emission value of the steel was selected as a constant value of $352 \mathrm{~kg}$ for $\mathrm{A} 1$ and $\mathrm{A} 3$, but the emission value of the concrete decreased by approximately $63 \%$ in A3 in comparison with A1. As a result of the evaluation of the results of total cost analyses, the costs of the wall system increase for A1 after $6 \mathrm{~m}$ excavation depth, although the dimensions of the wall were the same in A1 and A3. This situation may be raised as the result of the change of the contribution rates of the concrete and steel to the reinforced concrete design of the components of the structure, such as the front and back encasement of the base. The changes of the wall dimensions are also given in Figure 6 for comparison. Due to the attainment of a multiplexed number of outcomes, the details of the reinforcing bars are not shown in the context of the study. The change of the $\mathrm{CO}_{2}$ emission value of the concrete led to a change in the total $\mathrm{CO}_{2}$ emission value directly. The comparison of $\mathrm{A} 1$ and $\mathrm{A} 3$ showed that the change rate of the total $\mathrm{CO}_{2}$ emission of the envisaged design occurred between $50 \%$ and $60 \%$, depending on the change of concrete emission value by $63 \%$. The excavation depth is also the significant factor for $\mathrm{CO}_{2}$ emission. The increase of the excavation depth reduced the relative difference of the $\mathrm{CO}_{2}$ emission.

The comparison of Figure $6 \mathrm{~b}, \mathrm{c}$ reflects the effect of the change of the steel $\mathrm{CO}_{2}$ emission amount on the total emission. The $\mathrm{CO}_{2}$ emission value of the steel decreased in $\mathrm{A} 3$ at the rate of approximately $88 \%$ in comparison with A1. The dimensions of the wall changed after $5 \mathrm{~m}$ excavation depth and the base width of the wall in the analysis A2 became bigger than A3. In addition, the height of the wall decreased again in $\mathrm{A} 3$ analyses. On the contrary to this situation, the cost of the system in A3 was increasing nearly at a rate of $17 \%$. The aim of the section is to minimize the $\mathrm{CO}_{2}$ emissions, therefore the section is narrowed in $\mathrm{A} 3$ to reduce emissions, but the contribution rate of the steel within the reinforced concrete design is changed. This condition may lead the total costs to be higher than A2. The smallest values of $\mathrm{CO}_{2}$ emission were acquired in the $\mathrm{A} 3$ analysis. The relative difference of the $\mathrm{CO}_{2}$ emission amounts of the analyses $\mathrm{A} 2$ and $\mathrm{A} 3$ stayed between $52 \%$ and $60 \%$. All these comparisons show that the selection of the material process cannot be dependent on only the costs, but are also affected by the emission amounts of the structural materials for obtaining a sustainable design.

Figure 7 represents the same conditions as Figure 6, but only the unit costs of the materials are raised to their peak values. The increase of the material costs increased the total costs in all analyses, as expected. In Figure 7, the increase tendency of the dimensions of the analyses generally remained the same as Figure 6, but the main difference was caused by the increase of the total cost of the wall. The total cost raise is significantly bigger than the values obtained in Figure 6. Besides this, the relative difference between the determined values of total costs are decreased for $\mathrm{A} 1, \mathrm{~A} 2$, and $\mathrm{A} 3$. A1 and A3 possess similar design dimensions, but the relative $\mathrm{CO}_{2}$ emission difference is duplicated.

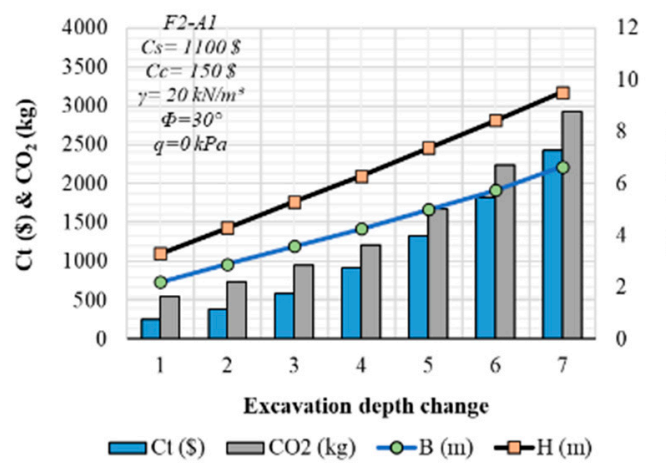

(a)

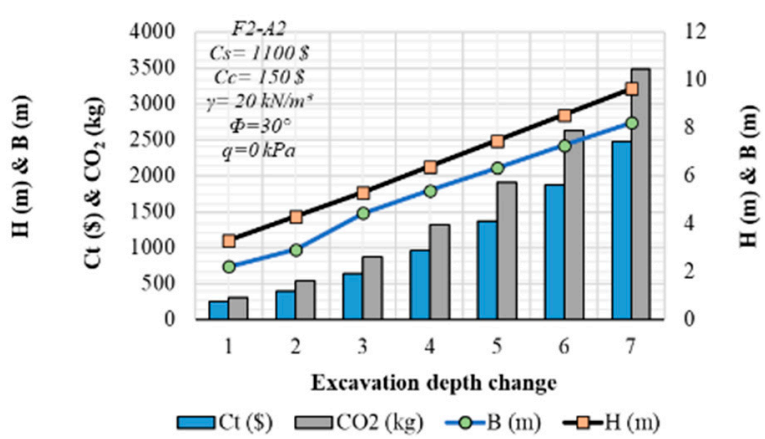

(b)

Figure 7. Cont. 


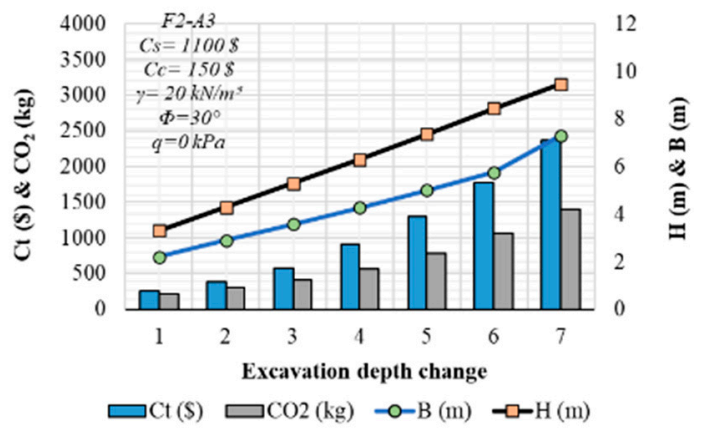

(c)

Figure 7. The change of $\mathrm{CO}_{2}$ emission and total cost against wall dimensions and the excavation depth $\left(\mathrm{C}_{\mathrm{c}}=150 \$, \mathrm{C}_{\mathrm{s}}=1100 \$, \mathrm{q}=0 \mathrm{kPa}\right)(\mathbf{a})$ Analysis 1, (b) Analysis 2, (c) Analysis 3.

Figure 8 represents the same conditions as Figure 7, but for this time, only the amount of surcharge has been raised to its peak value. The comparison of Figures 7 and 8 represents the surcharge load effect. In Figure 8, the foundation base width increases to maintain stability with the increased load value, while the wall height remains constant. Therefore, the inclination ratio of the foundation base width is raised. The total cost of the wall system has changed based on the increase of the base width, but it is not directly proportional. This results from the contribution rate of concrete and steel changing to only obtain the minimization of $\mathrm{CO}_{2}$ emission, and the dimensions of the wall components are differentiated to reach that aim.

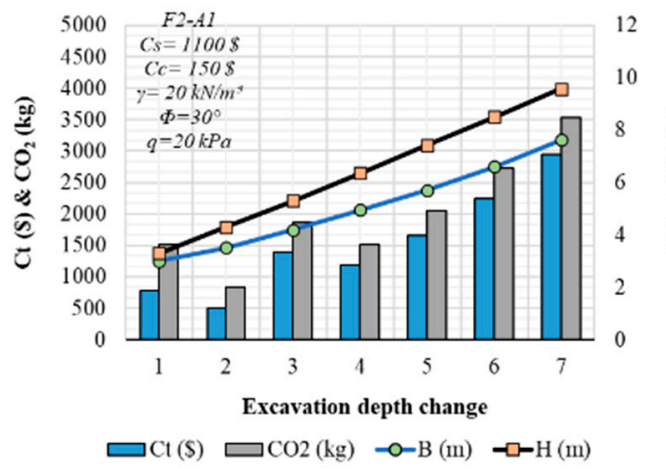

(a)

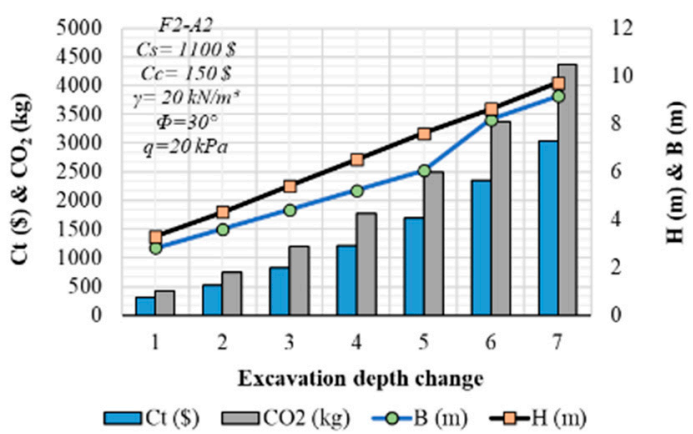

(b)

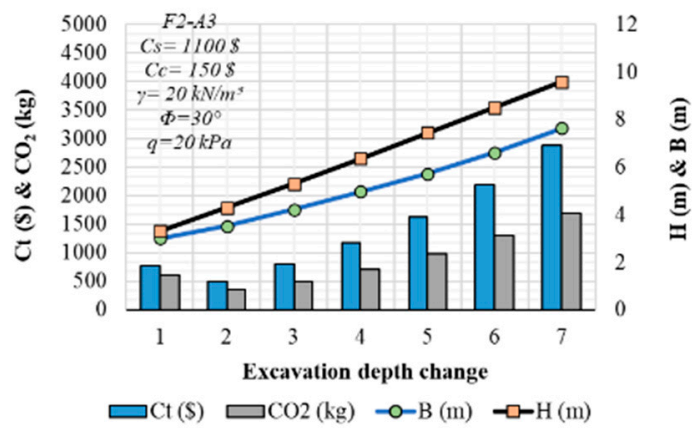

(c)

Figure 8. The change of $\mathrm{CO}_{2}$ emission and total cost against wall dimensions and the excavation depth $\left(C_{c}=150 \$, C_{s}=1100 \$, q=20 \mathrm{kPa}\right)(\mathbf{a})$ Analysis 1, (b) Analysis 2, (c) Analysis 3.

Figure 9 represents the difference in the values caused by the solution of two objective functions. The cost-based and the emission-based optimization logics are discussed with the evaluation of the results obtained at the same excavation depth. It was assumed that the excavation depth was $6 \mathrm{~m}$, 
the soil unit weight was $20 \mathrm{kN} / \mathrm{m}^{3}$, the shear strength angle was $30^{\circ}, \mathrm{C}_{\mathrm{c}}$ was $50 \$, \mathrm{C}_{\mathrm{s}}$ was $700 \$$, and the absence of the surcharge was envisaged. Figure $9 \mathrm{a}-\mathrm{d}$ are illustrated to reveal the effect of the selection of the objective function in terms of the total cost, the $\mathrm{CO}_{2}$ emission, the base width, and the height of the wall, respectively.

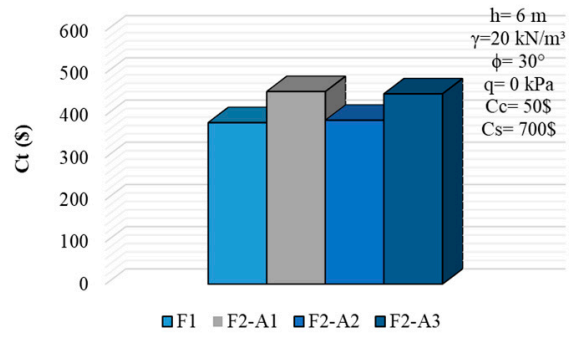

(a)

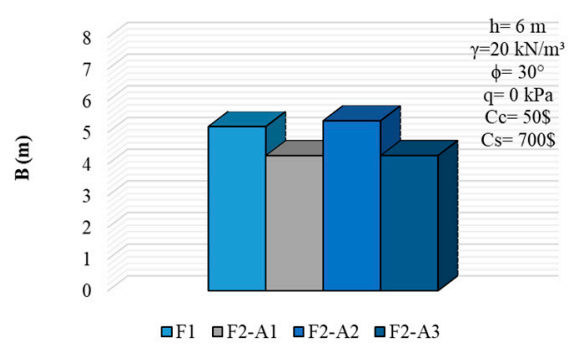

(c)

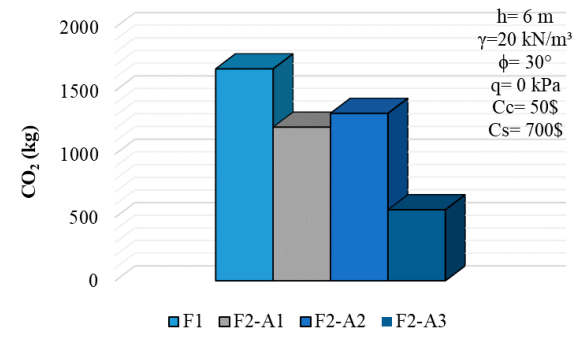

(b)

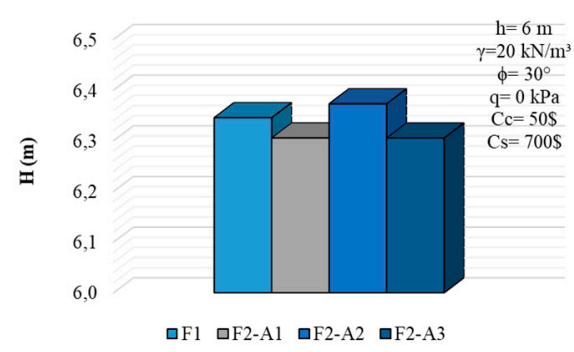

(d)

Figure 9. The effects of objective function logic: (a) change of total cost, (b) change of $\mathrm{CO}_{2}$ emission, (c) change of the width of the base, (d) change of the height of the wall.

In Figure 9a, F1 and F2-A2 solutions have similar results, while F2-A1 and F2-A3 are the same. Despite the usage of the emission values of $\mathrm{A} 1$ analyses for the F1 solutions, the cost values of F2-A1 were calculated to be bigger than F1. This is due to the tendency of F2 solution to decrease the emission. This situation can be seen in Figure 9b. The aim of the solution F1 is decreasing the cost and the function does not include any limitations or rates about the effects of $\mathrm{CO}_{2}$ emission. Therefore, the biggest emission value can be also obtained for the F1 solution. Figure 9c,d represent the dimensions of the wall system. F1 and F2-A2 solutions were found to be approximately the same. Although the similarity of the dimensions of $\mathrm{F} 1$ and $\mathrm{F} 2-\mathrm{A} 2$ are seen, the total $\mathrm{CO}_{2}$ emission values are very different from each other. This is dependent on the change of the emission value of the construction materials. As a result, F2-A3 analysis represents an eco-friendly solution for sustainable usage, but this solution is not cost-effective when a comparison is made between the other determined costs through objective functions. The complete evaluation of the divisions of Figure 9 shows that an integrated solution of both the cost and $\mathrm{CO}_{2}$ emission is essentially necessary.

Case 3: This case was related to the solution of objective function 3 (F3). The same analyses that were conducted in Case 2 were also performed in Case 3 to evaluate the integrated relationship of design, cost, and $\mathrm{CO}_{2}$ emission. Besides this, two different usages of $\mathrm{F} 3$ were tried within the context of this section. Equations (13) and (14) were used to discuss these two different usage conditions. In the application process of the first usage condition, the weight multipliers were assumed to be 0.5 to reflect an equal contribution rate of both cost and $\mathrm{CO}_{2}$ emission (Equation (13)). Then, in the application process of the second usage condition, two non-negative weights considering both cost and $\mathrm{CO}_{2}$ emission were taken as 1 (Equation (14)). Objective function 3 (F3) was calculated for three different couples of emission values of materials (A1, A2, A3) and additionally, the above-mentioned usage conditions were added to the solution sequence with the abbreviation of (1) and (2). (1) represents the solution of Equations (13) and (2) represents the solution of Equation (14). Figure 10 shows the change 
of the cost, the $\mathrm{CO}_{2}$ emission, and the dimensions of the wall system related to the used objective function. The whole parameters that were used in the analysis were selected as constant values and only the change of excavation depth is evaluated in the horizontal axis of the graphs shown in Figure 10. The abbreviations 1 to 7 that are given in the horizontal axis represent the change of excavation depth from 3 to $9 \mathrm{~m}$, respectively. The absence of surcharge load was taken into consideration and the unit weight of the soil was assumed to be $20 \mathrm{kN} / \mathrm{m}^{3}$, the shear strength was $30^{\circ}$, the unit cost of the concrete was 50 \$, and the unit cost of the steel was 700 \$. In Figure 10a, the solution of F3 (1)-A1, in Figure 10b the solution of F3 (1)-A2, in Figure 10c the solution of F3 (1)-A3, in Figure 10d the solution of F3 (2)-A1, in Figure 10e the solution of F3 (2)-A2, and Figure 10f the solution of F3 (2)-A3 function are given. When the total cost results given in the graphs are evaluated, the maximum change between the calculated values is approximately $19 \%$ and this result has been obtained especially for relatively deeper depths. In addition, in Figure 10, no significant change was found between the total heights of the walls, but the width of the foundation base was affected, depending on the change of solution functions, which attach importance to minimizing the $\mathrm{CO}_{2}$ emission of the structural system. In this connection, the emission values were also changed, subject to the change of the width of the base. The solution of function 3, depending on condition (1), shows the results with a unitless logic. Therefore, it can be true to say that the contribution rates of both the cost and the emission to the final evaluation of design are the same. In other words, the effects of the cost and the emissions are considered in the objective function and the design is affected from both variants within the same limits. The solution of function 3 depending on condition (2) shows the results with a similar solution approach like (1). The cost and emission values still have different units, but similar contribution rates to the objective function are used. So, it will be more explanatory to compare the results of the solutions of F3 all together to reach the final assessment.

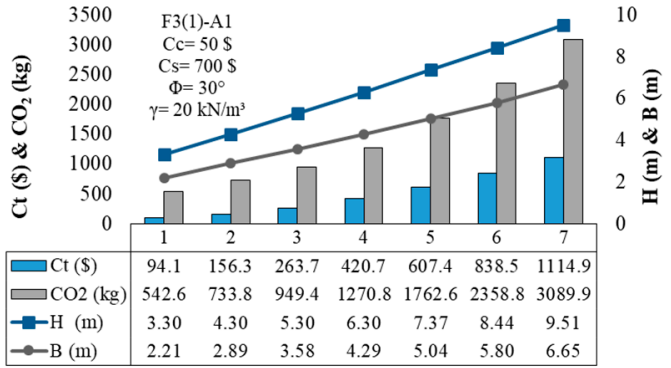

(a)

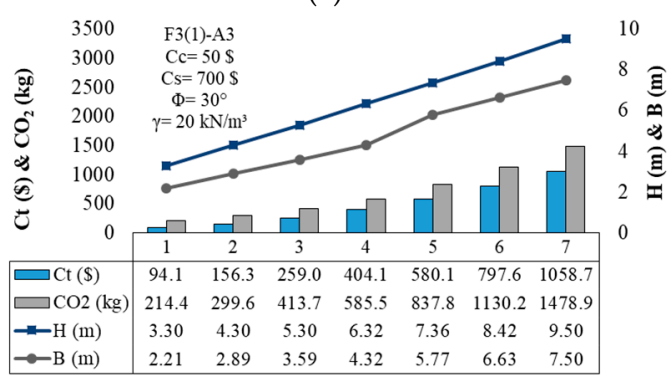

(c)

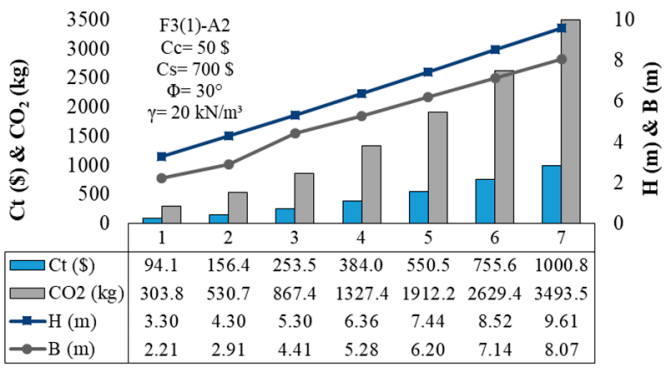

(b)

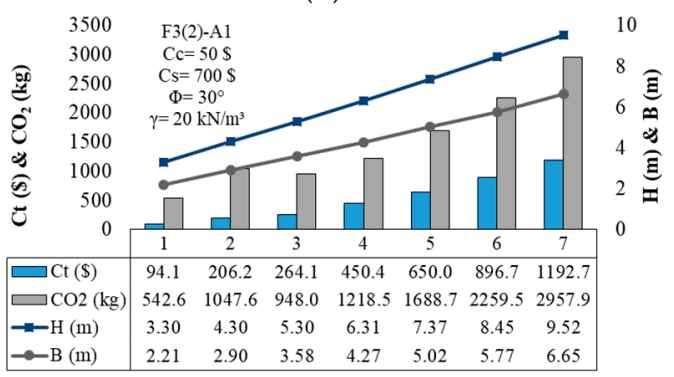

(d)

Figure 10. Cont. 


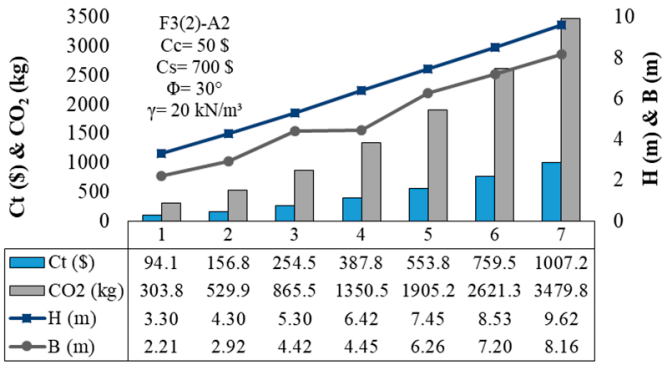

(e)

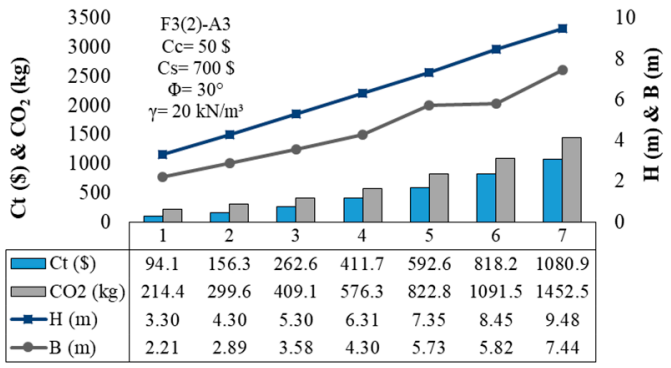

(f)

Figure 10. The change of total cost and $\mathrm{CO} 2$ emission against the width and height of the wall: (a) F3(1)-A1, (b) F3(1)-A2, (c) F3(1)-A3, (d) F3(2)-A1, (e) F3(2)-A2, (f) F3(2)-A3.

In Figure 11, the complete results of $\mathrm{C}_{\mathrm{t}}, \mathrm{CO}_{2}$ emission, $\mathrm{B}$, and $\mathrm{H}$ are given individually based on the solution function. In Figure $11 \mathrm{a}-\mathrm{d}$, the results of $\mathrm{Ct}, \mathrm{CO}_{2}$ emission, $\mathrm{B}$, and $\mathrm{H}$ are given, respectively. The evaluation of the graphs given in Figure 11 shows the huge change in $\mathrm{CO}_{2}$ emission values depending on the solution of the envisaged objective function. The use of the structural materials, which are special for less generation of gas emission, constitutes these significant differences between the obtained values. Analysis (3) involved the structural materials that have more specifically lower emission values than the materials used in the solution of the other two analyses. Therefore, the relative maximum difference of the obtained values of emission was obtained as a ratio of approximately $130-150 \%$ for all the excavation depths. This huge difference between the $\mathrm{CO}_{2}$ emission values has no significant effect on the total cost or the dimensions of the wall system except the values obtained for deep excavations. It will be true to conclude based on the results obtained within this study that the height of the wall is not as important a variable as the width of the foundation of the wall. In addition, if a comparison of the condition (1) and (2) is done, similar results for the total cost values, which were determined for the same analysis case, are attained, but the $\mathrm{CO}_{2}$ emission values are affected by the type of the conditions of solutions. The comparison of F3 (1) and F3 (2) and the results of the condition (1) presents more optimistic results than the results of the condition (2). In Figure 11c, the relative difference occurrence is similar for two kinds of solution conditions (F3 (1) and F3 (2)) to the same kind of analyses. The smallest width of the base was calculated for A1 analysis for both conditions. Due to the relatively high emission performance of the concrete used in analysis A1, the optimization process tries to reduce the concrete volume.

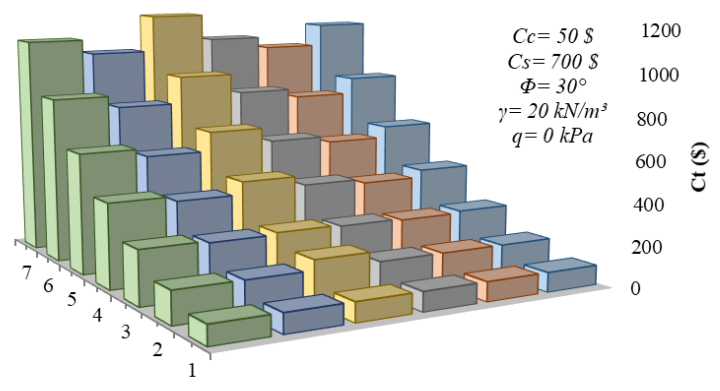

$\square F 3(1)-A 1 \quad \square F 3(1)-A 2 \quad \square F 3(1)-A 3 \quad \square F 3(2)-A 1 \quad \square F 3(2)-A 2 \quad \square F 3(2)-A 3$

(a)

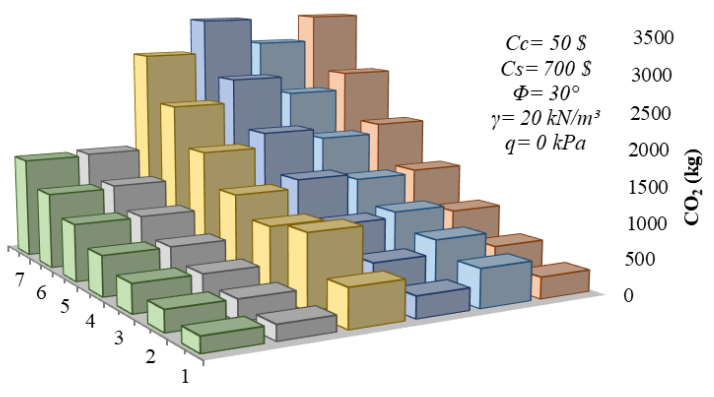

$\square F 3(1)-A 2 \quad \square F 3(1)-A 1 \quad \square F 3(2)-A 2 \quad \square F 3(2)-A 1 \quad$ 口F3(1)-A3 $\quad$ 口F3(2)-A3

(b)

Figure 11. Cont. 


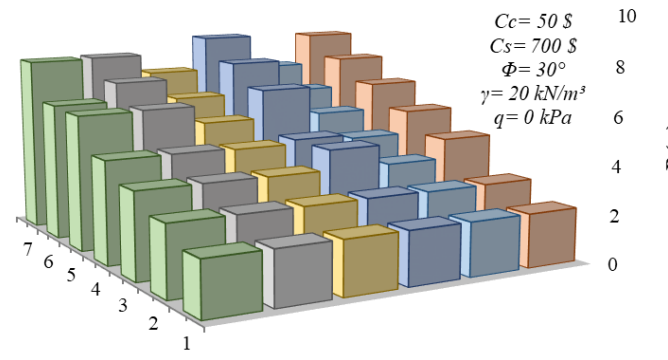

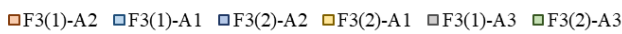

(c)

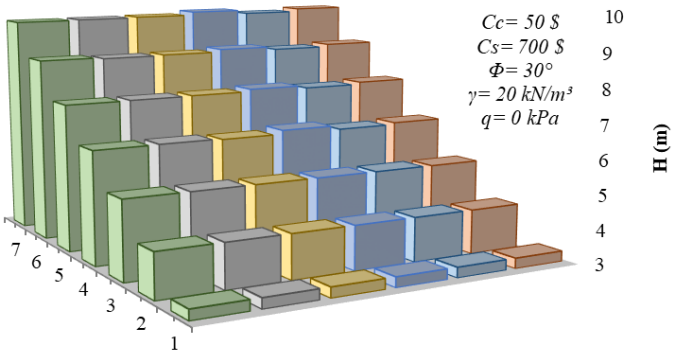

$\square F 3(1)-A 2 \quad \square F 3(1)-A 1 \quad \square F 3(2)-A 2 \quad \square F 3(2)-A 1 \quad \square F 3(1)-A 3 \quad \square F 3(2)-A 3$

(d)

Figure 11. The change in: (a) total cost, (b) $\mathrm{CO}_{2}$ emission, (c) width of foundation base, (d) total height of Table 3. The evaluations of the analyses have formed depending on the $9 \mathrm{~m}$ excavation depth. The results in both Figures 10 and 11 demonstrate that the utmost values of the changes which occurred were attained for the $9 \mathrm{~m}$ excavation depth. In Figure 12, the change in wall design, cost, and $\mathrm{CO}_{2}$ emission values against the change of unit weight of soil is given for the envisaged two different conditions F3 (1)-A1 and F3 (2)-A1.

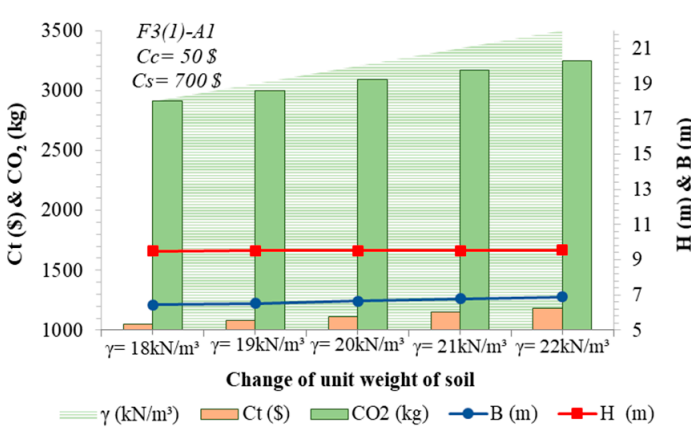

(a)

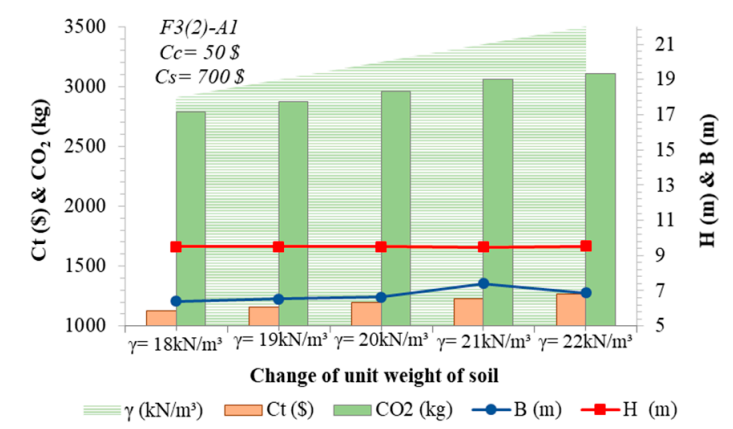

(b)

Figure 12. The change in $\mathrm{C}_{\mathrm{t}}, \mathrm{CO}_{2}$ emission, $\mathrm{B}, \mathrm{H}$ against the unit weight of soil (a) F3 (1)-A1, (b) F3 (2)-A1.

According to Figure 12, it is seen that the change in unit volume weight of soil does not cause a significant effect on the system dimensions. The relative change of the width of the base is nearly $7 \%$ and the relative change of the height of the wall is under $1 \%$ between the upper and lower boundaries envisaged for the change of unit weight of soil for both conditions. In addition, the relative change in the total cost and the $\mathrm{CO}_{2}$ emission is approximately $12 \%$ for both of the conditions between the upper and lower boundaries envisaged for the change of unit weight of soil. The increase in the soil unit weight increases all the variants differently. The cost of the wall system calculated for F3 (2) seems to be bigger than F3 (1), but this situation is the exact opposite for the $\mathrm{CO}_{2}$ emissions. The change in the surcharge loading amount is also investigated in Figure 13.

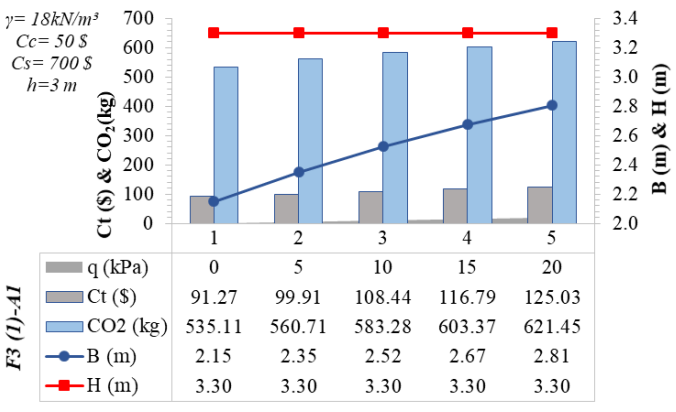

(a)

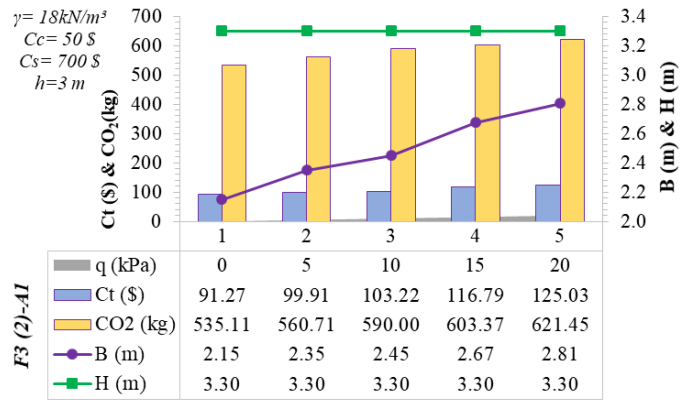

(b)

Figure 13. Cont. 


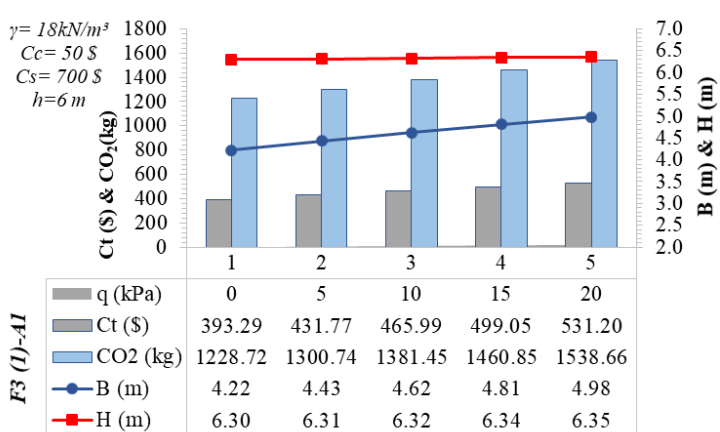

(c)

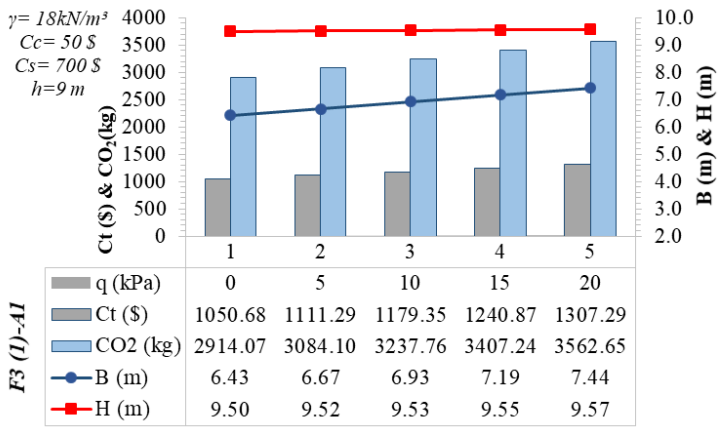

(e)

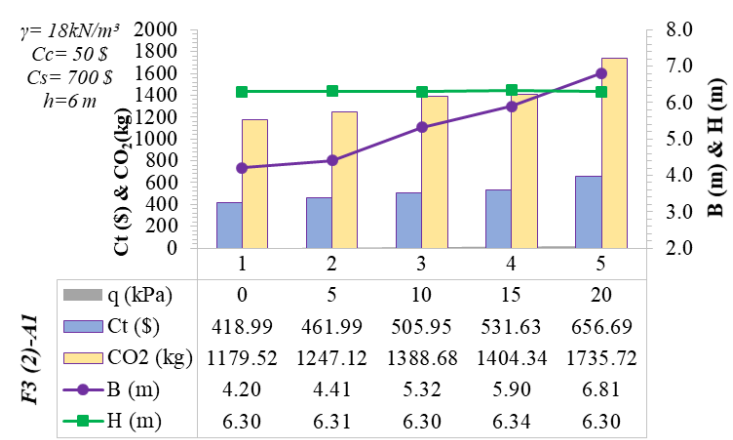

(d)

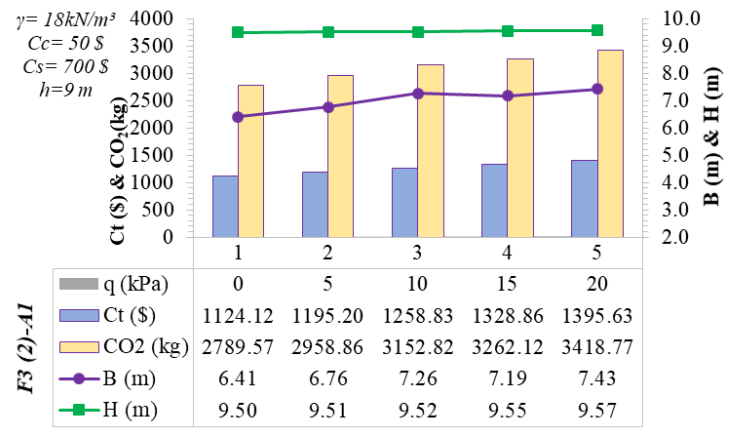

(f)

Figure 13. The effects of the surcharge loading amount: (a) $h=3 \mathrm{~m}-\mathrm{F} 3$ (1)-A1, (b) $h=3 \mathrm{~m}-\mathrm{F} 3$ (2)-A1, (c) h = 6 m- F3 (1)-A1, (d) h = 6 m- F3 (2)-A1, (e) h = 9 m- F3 (1)-A1, (f) h = 9 m- F3 (2)-A1.

The soil unit weight was $18 \mathrm{kN} / \mathrm{m}^{3}$, the unit cost of the concrete was $50 \$$ and the unit cost of the steel was $700 \$$ for all analyses conducted in Figure 13. It is clearly seen from Figure 13 that the most affected parameter because of the surcharge load increment was the width of the foundation. The width of the foundation increases, especially for smaller excavation depths, with the increasing amount of surcharge. The increasing ratio of the width of the base reduces based on the increase of the excavation depth. The least affected (or not at all) parameter from the surcharge load change was the wall height. Besides this, the cost of the system was affected according to the rise of the width of the foundation base and the $\mathrm{CO}_{2}$ emissions increased significantly for both analysis conditions (F3 (1) and F3 (2)).

In Figure 14, the change of unit cost of materials is investigated for $5 \mathrm{~m}$ excavation depth with $10 \mathrm{kPa}$ surcharge loading. The results were obtained from the solution of F3 (1)-A3. The unit cost of the concrete was assumed to be $50,75,100,125$, and $150 \$$ and is shown in the horizontal axis of the graphs with the representative abbreviations 1 to 5 . Besides this, the width of the foundation, the total cost, and the $\mathrm{CO}_{2}$ emission values were also evaluated depending on the change of unit cost of steel in the subdivisions of Figure 14. The decrease tendency of the foundation width according to the increase of steel and concrete was similar for the cases evaluated in Figure 14. The total cost of the wall system increased with the increase of the unit cost of the concrete. The increase of the unit cost of the steel can be also seen from the comparison of Figure 14a-d. The increase of the steel costs led the optimization algorithm to form an equilibrium between the increasing costs of the concrete. In addition, the emission values remained approximately the same for the increase of the concrete costs. 


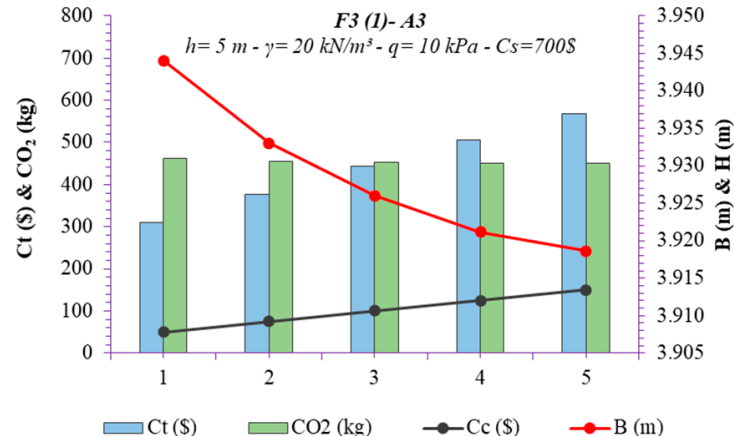

(a)

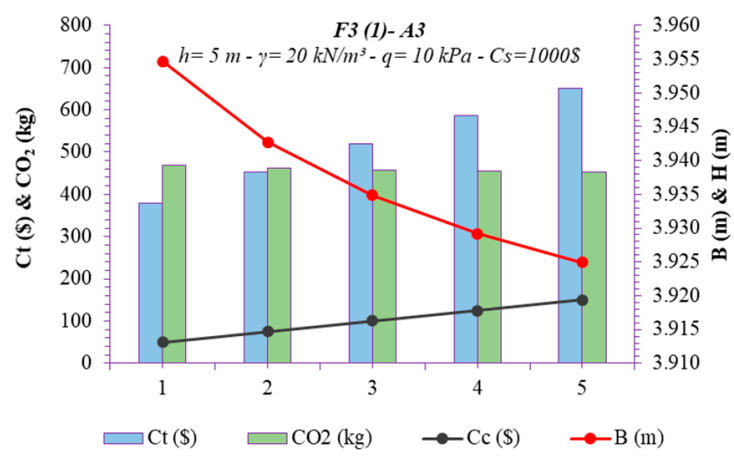

(c)

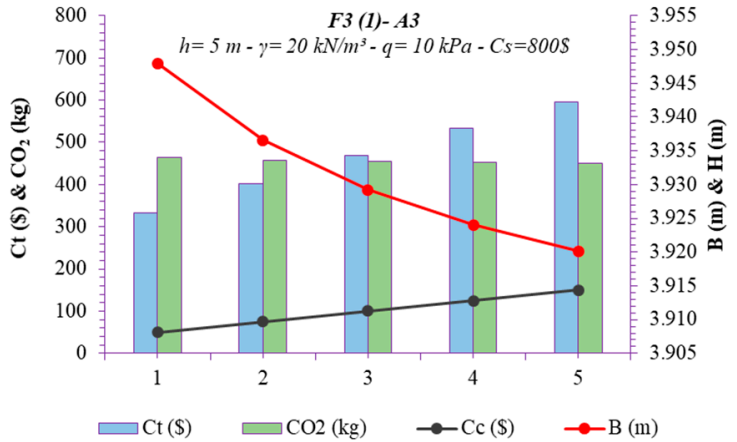

(b)

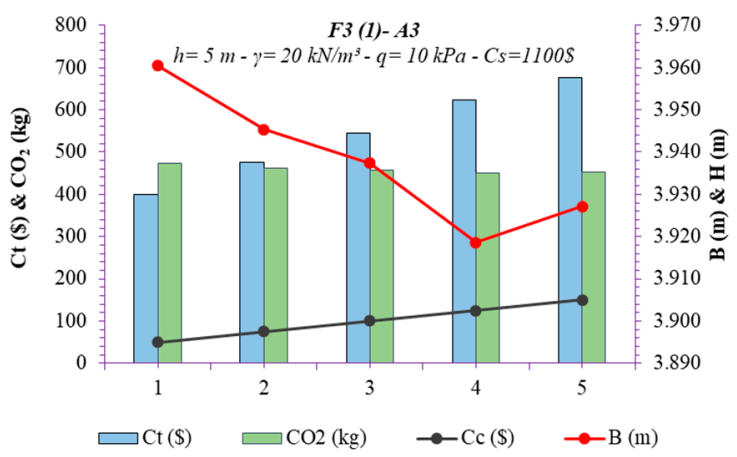

(d)

Figure 14. The effects of unit cost of structural materials: (a) $C_{s}=700 \$,(\mathbf{b}) C_{s}=800 \$,(\mathbf{c}) C_{s}=1000 \$$, (d) $C_{\mathrm{S}}=1100 \$$.

\section{Conclusions}

In this study, eco-friendly design requirements of the design problem of reinforced concrete retaining walls were investigated in relation to the cost minimization. For this purpose, within the context of this study, HS was used to calculate the minimization relationship between the cost and the $\mathrm{CO}_{2}$ emission for the reinforced concrete retaining walls via the performance of three different objectives. A total of 2251 parametric analyses were conducted to examine the appropriateness of the use of the HS for the design process of the retaining walls in relation with both cost and $\mathrm{CO}_{2}$ emission minimization, and 33,765 outcome data were attained in order to design the retaining wall. The retaining walls were assumed to be embedded in a pure cohesionless soil formation and the Rankine Earth Pressure Theory was used to calculate the lateral earth pressures caused by the soil mass. The shear strength angle of the soil formation was selected as a constant value, but the unit weight of the soil was assumed to be various in the analysis. Besides this, the excavation depth, the amount of the surcharge load, the unit cost, and the $\mathrm{CO}_{2}$ emission values of the structural materials were envisaged to be changeable. The first objective function (F1) was defined to search for the effects of the minimum cost quest against optimum dimensions. The second objective function (F2) was performed to acquire the most environmentally-friendly solution to construct retaining structures. The third objective function (F3) was prepared to search for the appropriateness of the use of the cost and $\mathrm{CO}_{2}$ emission minimization target together with the optimal dimensions, and the logic of this function was addressed with the division into two categories. In the first category (F3(1)), it was aimed to obtain the equivalent contribution rate with the use of logarithmic values of both cost and emission to acquire a unitless relationship, and the second category (F3(2)) was generated to investigate the compatibility of the cost and emissions by utilizing a well-accepted study of the literature. The $\mathrm{CO}_{2}$ emission values of concrete and steel were used as variables for the solution of F2 and F3 and an additional three different analyses were conducted (A1, A2, A3) to discover the influence of the material type used. 
The solution of the first objective function focused only on the cost minimization; therefore, the obtained results of the analyses do not mind the excessiveness of $\mathrm{CO}_{2}$ emission. The increase in the concrete material volume and the steel material weight leads to increased $\mathrm{CO}_{2}$ emissions in a general manner. The increase in the excavation depth always increases both the cost and emission values and seems to be the most important factor in the design. However, in the first objective function, the material costs are also a significant parameter to decide the dimensions. The increase in the unit cost of the concrete causes an increase in the steel densification to form stable construction. The increase in the unit cost of the steel constitutes a contrary situation and leads to ensuring the stability with the outgrowth of the concrete volume. This interactive solution logic may lead the emission value to be greater, especially if the concrete volume tends to increase over what is predicted.

The solution of the second objective function focused on the minimization of only $\mathrm{CO}_{2}$ emission values to ensure an eco-friendly design. However, at this stage, the emission values of the materials used formed the primary importance. The minority of the emission values of the materials caused an increase in the preferability phenomenon, but nothing was considered about the importance of the cost of the selection at that point. In addition, the decrease in the $\mathrm{CO}_{2}$ emission values can also be related to the used type of the material. The use of special materials also increases the costs and this condition directly effects the total costs of the construction works. This situation may cause an uncertainty in the design to decide if it is possible for both cost and $\mathrm{CO}_{2}$ emission savings can be obtainable. The results of objective function 2 presented these situations in a detailed view. Due to these reasons, it is indispensable to design the structural systems considering both the total cost and $\mathrm{CO}_{2}$ emission values together to procure both eco-friendly and sustainable design in relation with cost-effectiveness.

Objective function 3 provided an opportunity to ensure the essential design requirements mentioned by using two different perspectives. The increase of both the material costs and related $\mathrm{CO}_{2}$ emission values were taken into consideration and the contribution rates of these determinants were assumed to be half of the total function result. The outcomes of these objective functions were presented in an ordered relationship between design, cost, and emission with the use of graphical comparisons. All these comparisons differed from other studies in the literature in terms of evaluating the variables discussed and the results. It has been shown that the logic used in the analyses conducted in comparison with the research in the literature is feasible. In this regard, the outcomes of all the objective functions are summarized in Figure 15 in relation with the change of material costs.

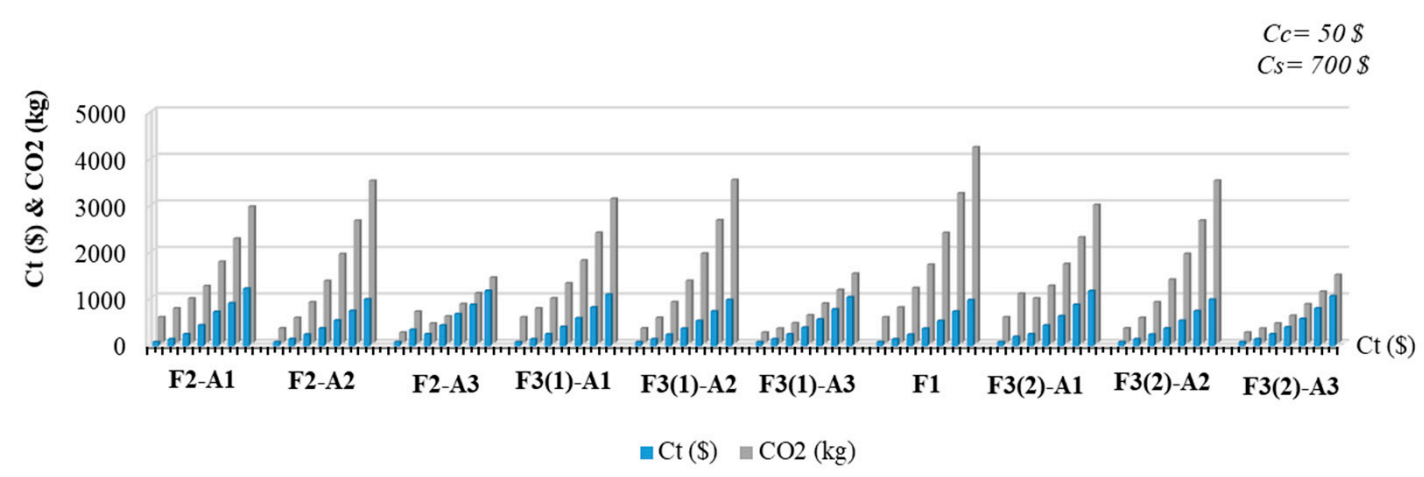

(a)

Figure 15. Cont. 


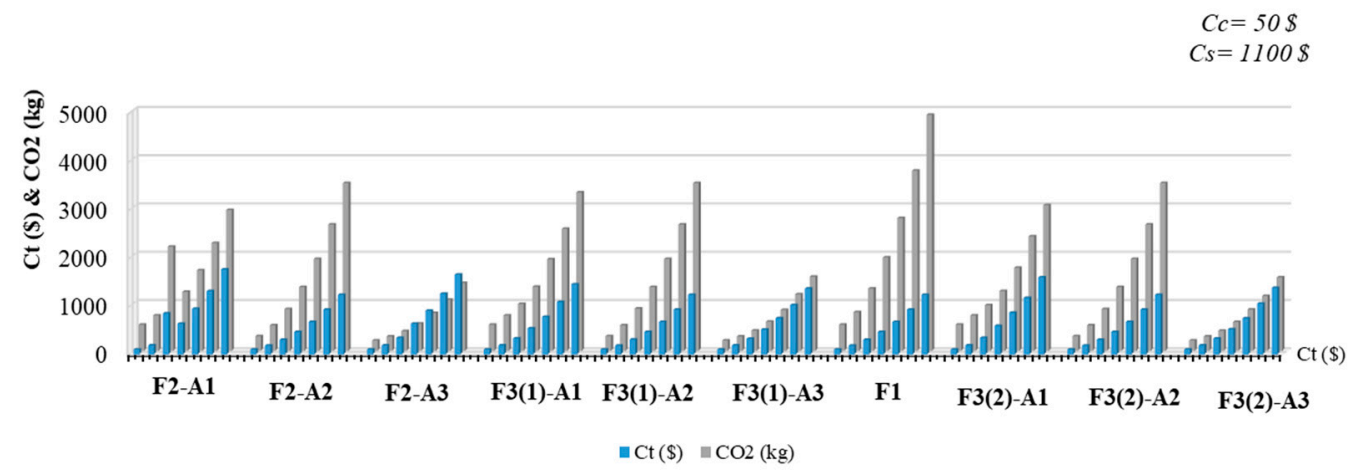

(b)

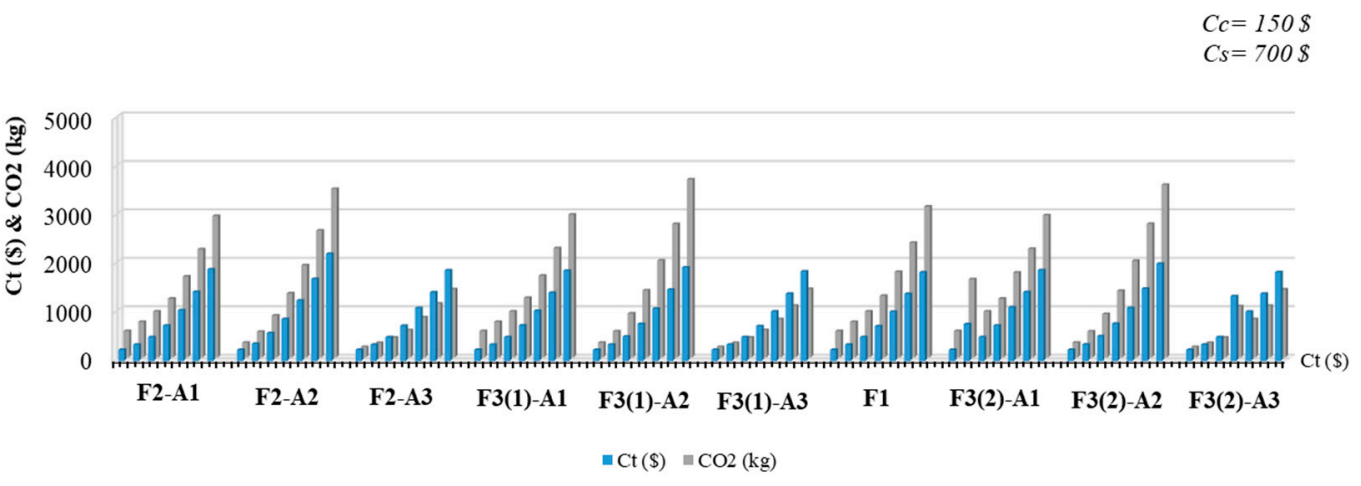

(c)

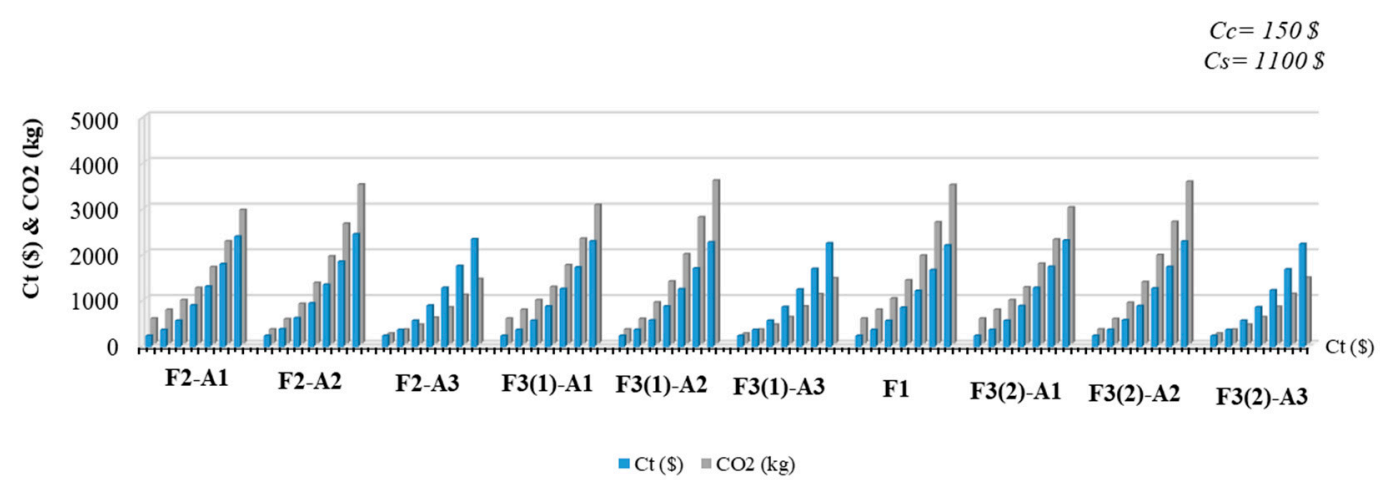

(d)

Figure 15. The change in total cost and $\mathrm{CO}_{2}$ emission values against the objective function and the unit cost of the structural materials: (a) $C_{s}=50 \$$ and $C_{s}=700 \$,(b) C_{s}=50 \$$ and $C_{s}=1100 \$,(\mathbf{c}) C_{s}=150 \$$ and $C_{\mathrm{s}}=700 \$,(\mathbf{d}) \mathrm{C}_{\mathrm{s}}=150 \$$ and $\mathrm{C}_{\mathrm{s}}=1100 \$$.

As a result of the interpretation of the presented graphics, if the material costs are at the lower boundary of the identified values, the F2-A3, F3(1)-A3, and F3(2)-A3 solutions seem to be applicable for a sustainable design attainment (Figure 15a). The results of F2 gave similar approaches to F3 functions, although it only considered the minimization of $\mathrm{CO}_{2}$ emissions. All of the objective functions with the minimum values of emission of materials were determined with the use of $\mathrm{A} 3$ analysis. The maximum $\mathrm{CO}_{2}$ emission was obtained by the use of $\mathrm{F} 1$, although the minimum cost attainment was ensured. However, this situation does not reveal an acceptable approach in terms of environmentally-friendly construction works.

Figure $15 \mathrm{~b}$ presents the results of the objective functions if the cost of the steel is raised to its highest boundary that was foreseen in the context of this study. The rise in steel cost increased the total cost of the system, as expected. The results of F2-A3, F3(1)-A3, and F3(2)-A3 remained approximately 
similar to each other, but the relative differences between other defined solutions decreased, especially for the total costs. The rise in the steel costs led to a decrease in the amount of steel used in the design for $\mathrm{F} 1$, and this condition caused an increase in the $\mathrm{CO}_{2}$ emission amount for $\mathrm{F} 1$ unexpectedly, according to the increase of the used amount of the concrete contribution in reinforced concrete.

In Figure 15c, the cost of the steel remains at the lower boundary of the envisaged values and the concrete cost is increased to its highest value. The emission values of $\mathrm{A} 3$ analyses were still closer to each other, but the relative differences between the $\mathrm{CO}_{2}$ emission values of other $\mathrm{A} 1$ and $\mathrm{A} 2$ analyses were reduced. The costs of the retaining wall design increased, but the relative difference between the costs reduced. In Figure 15d, the costs of the structural materials were raised to their highest values. The $\mathrm{CO}_{2}$ emission values were closer to the values obtained in Figure $15 \mathrm{c}$, but the costs of the wall increased gradually with the increasing costs. Besides this, the comparison of Figure $15 a-d$ shows that the increase of steel cost and steel amount can be ensured the minimization of $\mathrm{CO}_{2}$ emission.

Consequently, it is a brief result to prefer special materials in construction with low $\mathrm{CO}_{2}$ emission characteristics to get an eco-friendly design, but the cost-effective design must be procurable to ensure production efficiency. The use of optimization techniques, including both the effects of cost and $\mathrm{CO}_{2}$ emissions in relation, seems to be more useful to find the most appropriate solution results for design considerations. Concordantly, the use of HS seems to be preferable according to the presentation of user-friendly easiness to define multi-objective functions. It must be noted that the design is not only based on the selection of appropriate techniques used to find the optimal solution, but also depends on the selection of materials that are fit to purpose.

In future works, the robustness of different metaheuristic algorithms and hybrid algorithms can be investigated for eco-friendly optimum design of RC retaining walls. Additionally, the different combination weightings of two objectives, such as cost and $\mathrm{CO}_{2}$ emissions, can be investigated.

Author Contributions: G.B. and A.E.K. generated the analysis codes and numerical cases. G.B., A.E.K. and Z.A.A. developed the theory background and formulations of the system. The text of the paper was formed by Z.A.A. and S.M.N. Z.W.G. supervised the research direction. All authors have read and agreed to the published version of the manuscript.

Funding: This work was supported by the National Research Foundation of Korea (NRF) grant funded by the Korea government (MSIT) (2020R1A2C1A01011131). This research was also supported by the Energy Cloud R\&D Program through the National Research Foundation of Korea (NRF) funded by the Ministry of Science, ICT (2019M3F2A1073164).

Conflicts of Interest: The authors declare no conflict of interest.

\section{References}

1. Frangopol, D.M. Life-cycle performance, management, and optimisation of structural systems under uncertainty: Accomplishments and challenges. Struct. Infrast. Eng. 2011, 7, 389-413. [CrossRef]

2. Yepes, V.; Martí, J.V.; García, J. Black Hole Algorithm for Sustainable Design of Counterfort Retaining Walls. Sustainability 2020, 12, 2767. [CrossRef]

3. Baglivo, C.; Congedo, P.M. Design method of high performance precast external walls for warm climate by multi-objective optimization analysis. Energy 2015, 90, 1645-1661. [CrossRef]

4. Dombayc1, O.A.; Golcü, M.; Pancar, Y. Optimization of insulation thickness for external walls using different energy-sources. Appl. Energy 2006, 83, 921-928. [CrossRef]

5. Aydogdu, I.; Akin, A. Biogeography Based $\mathrm{CO}_{2}$ and Cost Optimization of RC Cantilever Retaining Walls, World Academy of Science, Engineering and Technology. Int. J. Civ. Environ. Eng. 2015, 2. Available online: https://www.semanticscholar.org/paper/Biogeography-Based-CO2-and-Cost-Optimizationof-RC-Aydogdu-Ak\%C4\%B1n/176b1134b768ee30091e4c415e69632050248abd\#paper-header (accessed on 28 July 2020).

6. Li, Z. Development and Application of Eco-Friendly Concrete. Adv. Mater. Res. 2011, 250-253, 3827-3836. [CrossRef]

7. Habert, G.; Roussel, N. Study of two concrete mix design strategies to reach carbon mitigation objectives. Cem. Concr. Compos. 2009, 31,397-402. [CrossRef] 
8. Aguado, A.; Caño, A.D.; de la Cruz, M.P.; Gomez, D.; Josa, A. Sustainability assessment of concrete structures within the Spanish structural concrete code. J. Constr. Eng. Manag. 2012, 138, 268-276. [CrossRef]

9. Molina-Moreno, F.; Martí, J.V.; Yepes, V. Optimization of buttressed earth retaining walls using hybrid harmony search algorithms. Eng. Struct. 2017, 134, 205-216. [CrossRef]

10. Molina-Moreno, F.; Martí, J.V.; Yepes, V. Carbon embodied optimization for buttressed earth-retaining walls: Implications for low-carbon conceptual designs. J. Clean. Prod. 2017, 164, 872-884. [CrossRef]

11. Khajehzadeh, M. A new hybrid algorithm for $\mathrm{CO}_{2}$ emissions optimization of retaining walls. Int. J. Adv. Mech. Civ. Eng. 2016, 3, 7-11.

12. Villalba, P.; Alcala, J.; Yepes, V.; Gonzales-Vidosa, F. $\mathrm{CO}_{2}$ optimization of reinforced concrete cantilever retaining walls. In Proceedings of the 2nd International Conference on Engineering Optimization, Lisbon, Portugal, 6-9 September 2010.

13. Yepes, V.; Gonzalez-Vidosa, F.; Alcala, J.; Villalba, P. $\mathrm{CO}_{2}$-optimization design of reinforced concrete retaining walls based on a VNS-threshold acceptance strategy. J. Comput. Civ. Eng. 2012, 26, 378-386. [CrossRef]

14. Bezerra, J.V.A.; Mota, T.G.; Andrade, H.M.L.S.; Andrade, L.P.; Vigoderis, R.B. Comparative Study of Retaining Walls Aiming To Optimize Carbon Footprint. Rev. Ibero Am. Ciências Ambient. 2020, 11, 460-467. [CrossRef]

15. Zastrow, P.; Molina-Moreno, F.; García-Segura, T.; Martí, J.V.; Yepes, V. Life cycle assessment of cost-optimized buttress earth-retaining walls: A parametric study. J. Clean. Prod. 2017, 140, 1037-1048. [CrossRef]

16. Yeo, D.H.; Potra, F.A. Sustainable design of reinforced concrete structures through $\mathrm{CO}_{2}$ emission optimization. J. Struct. Eng. 2015, 141, 3. [CrossRef]

17. Yoon, Y.C.; Kim, K.H.; Lee, S.H.; Yeo, D. Sustainable design for reinforced concrete columns through embodied energy and $\mathrm{CO}_{2}$ emission optimization. Energy Build. 2018, 174, 44-53. [CrossRef]

18. Sierra, L.A.; Pellicer, E.; Yepes, V. Social sustainability in the life cycle of Chilean public infrastructure. J. Constr. Eng. Manag. 2016, 142, 05015020. [CrossRef]

19. Sierra, L.A.; Yepes, V.; García-Segura, T.; Pellicer, E. Bayesian network method for decision-making about the social sustainability of infrastructure projects. J. Clean. Prod. 2018, 176, 521-534. [CrossRef]

20. Pons, J.J.; Penadés-Plà, V.; Yepes, V.; Martí, J.V. Life cycle assessment of earth-retaining walls: An environmental comparison. J. Clean. Prod. 2018, 192, 411-420. [CrossRef]

21. Lee, D.; Kang, G.; Nam, C.; Cho, H.; Kang, K.I. Stochastic Analysis of Embodied Carbon Dioxide Emissions Considering Variability of Construction Sites. Sustainability 2019, 11, 4215. [CrossRef]

22. De Medeiros, G.F.; Kripka, M. Optimization of reinforced concrete columns according to different environmental impact assessment parameters. Eng. Struct. 2014, 59, 185-194. [CrossRef]

23. Bacanin, N.; Bezdan, T.; Tuba, E.; Strumberger, I.; Tuba, M. Monarch Butterfly Optimization Based Convolutional Neural Network Design. Mathematics 2020, 8, 936. [CrossRef]

24. Abd Elaziz, M.; Xiong, S.; Jayasena, K.P.N.; Li, L. Task scheduling in cloud computing based on hybrid moth search algorithm and differential evolution. Knowl. Based Syst. 2019, 169, 39-52. [CrossRef]

25. Ghosh, S.; Kaur, M.; Bhullar, S.; Karar, V. Hybrid abc-bat for solving short-term hydrothermal scheduling problems. Energies 2019, 12, 551. [CrossRef]

26. Coulomb, C.A. Essai sur une Application des Regles des Maximis et Minimis a Quelques Problemes de Statique Relatifs a L'artitecture; De l'Imprimerie Royale: Paris, France, 1776.

27. Rankine, W.J.M. II. On the stability of loose earth. Philos. Trans. R. Soc. Lond. 1857, 147, 9-27. [CrossRef]

28. Boussinesq. Sur la détermination de l'épaisseur minima que doit avoir un mur vertical d'une hauteur et d'une densité données, pour contenir un massif terreux sans cohésion, dont la surface supérieure est horizontale. Ann. Ponts Chaussées 1882, III, 625.

29. Terzaghi, K.V. General wedge theory of earth pressure, Transactions. ASCE 1941, 106, 68-97.

30. Jaky, J. The coefficient of earth pressure at rest. J. Soc. of Hung. Arch. Engrs. 1944, 78, 355-358.

31. Dembicki, E.; Chi, T. System analysis in calculation of cantilever retaining walls. Int. J. Numerical Anal. Methods Geomech. 1989, 13, 599-610. [CrossRef]

32. Powrie, W. Limit equilibrium analysis of embedded retaining walls. Geotechnique 1996, 46, 709-723. [CrossRef]

33. Bowles, J.E. Foundation Analysis and Design; McGraw-Hill: New York, NY, USA, 1988.

34. Yıldırım, S. Zemin Incelemesi ve Temel Tasarımı; Birsen Yayınevi: Fatih/İstanbul, Turkey, 2002.

35. Sasidhar, T.; Neeraja, D.; Samba, V.; Sudhindra, M. Application of genetic algorithm technique for optimizing design of reinforced concrete retaining wall. Int. J. Civ. Eng. Technol. 2017, 8, 999-1007. 
36. American Concrete Institute. Building Code Requirements for Structural Concrete and Commentary; ACI Committee: Farmington Hills, MI, USA, 2014; ISBN 978-0870317446.

37. Saribas, A.; Erbatur, F. Optimization and sensitivity of retaining structures. J. Geotech. Eng. 1996, 122, 649-656. [CrossRef]

38. Rhomberg, E.J.; Street, W.M. Optimal design of retaining walls. J. Struct. Div. 1981, 107, 992-1002.

39. Alshawi, F.A.N.; Mohammed, A.I.; Farid, B.J. Optimum design of tied-back retaining walls. Struct. Eng. 1988, 66, 97-105.

40. Keskar, V.; Adidam, S.R. Minimum cost design of a cantilever retaining wall. Indian Concr. J. 1989, 63, 401-405.

41. Pochtman, Y.M.; Zhmuro, O.V.; Landa, M.S. Design of an optimal retaining wall with anchorage. Soil Mech. Found. Eng. 1988, 25, 508-510. [CrossRef]

42. Chau, K.W.; Albermani, F. Knowledge-based system on optimum design of liquid retaining structures with genetic algorithms. J. Struct. Eng. 2003, 129, 1312-1321. [CrossRef]

43. Sivakumar Babu, G.L.; Basha, B.M. Optimum design of cantilever retaining walls using target reliability approach. Int. J. Geomech. 2008, 8, 240-252. [CrossRef]

44. Geem, Z.W.; Kim, J.H.; Loganathan, G.V. A new heuristic optimization algorithm: Harmony search. Simulation 2001, 76, 60-68. [CrossRef]

45. Askarzadeh, A.; Rashedi, E. Harmony Search Algorithm: Basic Concepts and Engineering Applications. In Intelligent Systems: Concepts, Methodologies, Tools, and Applications; IGI Global: Hershey, PA, USA, 2018; pp. 1-30.

46. Ulusoy, S.; Kayabekir, A.E.; Bekdaş, G.; Nigdeli, S.M. Optimum Design of Reinforced Concrete Multi-Story Multi-Span Frame Structures under Static Loads. Int. J. Eng. Technol. 2019, 10, 403-407. [CrossRef]

47. Ulusoy, S.; Kayabekir, A.E.; Bekdaş, G.; Nigdeli, S.M. Metaheuristic Algorithms in Optimum Design of Reinforced Concrete Beam by Investigating Strength of Concrete. Chall. J. Concr. Res. Lett. 2020, 11, 33-37. [CrossRef]

48. Cakiroglu, C.; Bekdaş, G.; Geem, Z.W. Harmony Search Optimisation of Dispersed Laminated Composite Plates. Materials 2020, 13, 2862. [CrossRef] [PubMed]

49. Cakiroglu, C.; Bekdaş, G.; Kim, S.; Geem, Z.W. Optimisation of Shear and Lateral-Torsional Buckling of Steel Plate Girders Using Meta-Heuristic Algorithms. Appl. Sci. 2020, 10, 3639. [CrossRef]

50. Kayabekir, A.E.; Toklu, Y.C.; Bekdaş, G.; Nigdeli, S.M.; Yücel, M.; Geem, Z.W. A Novel Hybrid Harmony Search Approach for the Analysis of Plane Stress Systems via Total Potential Optimization. Appl. Sci. 2020, 10, 2301. [CrossRef]

51. Toklu, Y.C.; Bekdaş, G.; Geem, Z.W. Harmony Search Optimization of Nozzle Movement for Additive Manufacturing of Concrete Structures and Concrete Elements. Appl. Sci. 2020, 10, 4413. [CrossRef]

52. FHWA-IF-99-015, Geotechnical Engineering Circular No. 4 Ground Anchors and Anchored Systems; Federal Highway Administration: Washington, DC, USA, 1999.

53. Kazı Çukurlarının Stabilitesi ve İksa Sistemi Etüt, Proje, Uygulama ve Kontrolleri ile İlgili Uyulacak Esaslar hakkında Kazı Güvenliği ve Alınacak Önlemler; Çevre ve şehircilik Bakanlığı: Ankara, Turkey, 2018.

54. British Standards Institution. Eurocode 7: Part 1, General Rules; British Standards Institution: London, UK, 1995.

55. Camp, C.V.; Akin, A. Design of Retaining Walls Using Big Bang-Big Crunch Optimization. J. Struct. Eng. ASCE 2012, 138, 438-448. [CrossRef]

56. Paya-Zaforteza, I.; Yepes, V.; Hospitaler, A.; Gonzalez-Vidosa, F. $\mathrm{CO}_{2}$-optimization of reinforced concrete frames by simulated annealing. Eng. Struct. 2009, 31, 1501-1508. [CrossRef]

57. Yang, X.S. Flower pollination algorithm for global optimization. In International Conference on Unconventional Computing and Natural Computation; Springer: Berlin/Heidelberg, Germany, 2012; pp. 240-249.

(C) 2020 by the authors. Licensee MDPI, Basel, Switzerland. This article is an open access article distributed under the terms and conditions of the Creative Commons Attribution (CC BY) license (http://creativecommons.org/licenses/by/4.0/). 